\title{
Agroecological management of cucurbit-infesting fruit fly: a review
}

\author{
Jean-Philippe Deguine • Toulassi Atiama-Nurbel • \\ Jean-Noël Aubertot $•$ Xavier Augusseau • \\ Morguen Atiama $\cdot$ Maxime Jacquot $\cdot$ Bernard Reynaud
}

Accepted: 23 January 2015 / Published online: 5 March 2015

(C) INRA and Springer-Verlag France 2015

\begin{abstract}
Conventional crop protection with pesticides has limitations such as resistance of pests to pesticides and faunal imbalance. Agroecological crop protection is an attractive alternative based on the principles of agroecology. We present here this strategy using the case of Cucurbitaceae flies, which are the most important agricultural pests in Réunion. Research has been carried out on the bioecology of these insects and on the effectiveness of agroecological techniques. The main points are the following: the number of species of vegetable flies increased in the southern summer. Adult flies spend more than $90 \%$ of their time on nonhost plants, with specific circadian rhythms. Several original agroecological techniques were designed, such as sanitation using augmentoria; trap plants, e.g., maize; adulticide bait; and the creation of habitats for predatory arthropods. Local growers are very satisfied with the results. They have reduced insecticide use with substantial cost savings and they have
\end{abstract}

J.-P. Deguine $(\varangle) \cdot$ M. Atiama $\cdot$ M. Jacquot $\cdot$ B. Reynaud CIRAD, UMR PVBMT_Peuplements Végétaux et Bioagresseurs en Milieu Tropical, 7 chemin de l'IRAT 97410, Saint-Pierre, Réunion, France

e-mail: jean-philippe.deguine@cirad.fr

T. Atiama-Nurbel

ARMEFLHOR, 1 chemin de l'IRFA, Bassin Martin,

97410 Saint-Pierre, Réunion, France

J.-N. Aubertot

INRA, UMR1248 AGIR, F-31326 Castanet Tolosan, France

X. Augusseau

CIRAD, UMR TETIS - Territoires, environnement, télédétection et information spatiale, TA C-91 / MTD - Maison de la Télédétection, 500 rue Jean-François Breton, 34398 Montpellier Cedex 5, France observed a decrease in losses and a lower phytosanitary workload. The education and training of students, professionals, and the general public has been a major aspect of this project. Increased knowledge of flies and agroecological management strategies of their populations can now be combined with modeling tools to facilitate the extension of the program to other areas or for educational purposes. Practices are currently being extended to other areas of the island and other countries of the Indian Ocean. This project is both a significant milestone for organic farming in Réunion and a precedent for other initiatives aimed at reducing or eliminating pesticides.

Keywords Agroecology · Crop protection · Organic farming · Tephritidae $\cdot$ Réunion

Contents

1. Introduction

2. Agroecology applied to crop protection

3. The problem of cucurbit-infesting fruit flies worldwide and in Réunion

4. Results on the bioecology of cucurbit flies

5. Relevance of agroecological population management techniques

6. Technology, economical trends, and knowledge transfer

7. Modeling perspectives

8. Conclusion Acknowledgements

9. References 


\section{Introduction}

Crop protection has long relied on agrochemicals but is now at a defining moment. Although pesticides have been condemned for many years (Carson 1962), the problems encountered with this type of crop protection are becoming more frequent and acute: inefficiency in many situations; resistance to pesticides; soil, water, and air pollution; hazards to human health; and loss of biodiversity (Pimentel 2002). The challenge is now to move from this chemical-based approach to one of pest prevention with more balanced and sustainable agroecosystems. This approach is based on agroecological management of plant and animal communities at extended scale, spatiotemporal management (Deguine et al. 2008).

This paper summarizes the results obtained from the agroecological control of cucurbit flies (kingdom Animalia; phylum Arthropoda; class Insecta; order Diptera; family Tephritidae) in Réunion. The paper will first underline the basics of agroecology and its use in crop protection through the concept of "agroecological crop protection," which focuses in particular on the role of biodiversity and conservation biological control (Altieri 1999; Barbosa 1999; Costa et al. 2012; Ferron and Deguine 2005; Hole et al. 2005; Landis et al. 2000; Moonen and Bàrberi 2008; Norris and Kogan 2000; Simon et al. 2014; Swift et al. 2004; Wratten et al. 1998, 2003). Secondly, we will present the Tephritidae, major pests in fruit and vegetable agroecosystems around the world and the most dangerous for Réunionese agriculture, while providing a framework for agroecological management of Cucurbitaceae flies in Réunion. This summary provides the results of our research; firstly, on the biology, ecology, and population dynamics of flies and, secondly, on the development of a package of agroecological techniques for fly population control. Following an original experience (a research and development project called Agroecological Management of Vegetables Flies in Réunion (GAMOUR)) on farms between 2009 and 2011 (Augusseau et al. 2011), socioeconomic impacts will be discussed, confirming the success of the techniques. Finally, we will discuss the dissemination of information and knowledge and benefits for the various stakeholders.

\section{Agroecology applied to crop protection}

The evolution of crop protection has been described by many authors (Deguine et al. 2008; Horowitz and Ishaaya 2004; Norris et al. 2003; Pimentel 2002; Van Lenteren et al. 1992). This has been achieved by the emergence of different techniques of which the best known is certainly integrated pest management (Ehler 2006; Ehler and Bottrell 2000; Koul et al. 2004). Since the late twentieth century, a strong trend has led researchers and farmers to reduce the use of chemical pesticides, particularly because of its negative impact (on the environment and health) as well as disadvantages (high cost, low efficiency) (Ferron 1999; Pesson 1990; Popp et al. 2013; Van den Bosch and Aeschlimann 1986). However, this reduction in the use of agrochemicals has seen the development of environmental, ecology-based solutions (Koul and Cuperus 2007; Landis et al. 2000; Pimentel and Goodman 1978; Shennan et al. 2005), including southern tropical countries (Altieri et al. 2012; Wyckhuys et al. 2013).

\subsection{The emergence of the science of agroecology}

The use of agroecological techniques in agriculture is not a new idea. Hénin (1967) defined agronomy as "an ecology applied to the production of crops and management of agricultural land." Agricultural activities are similarly not excluded in the original definition of ecology by Haeckel (1866): "The study of the natural environment including the relations of organisms to one another and to their surroundings."

In more recent plant protection, the Earth Summit in Rio de Janeiro in 1992 was probably just as significant, if not more, than the discovery of synthetic pesticides. Stressing the importance of biodiversity in sustainable ecosystems, it highlighted agriculture as a major cause of biodiversity reduction, especially nonselective methods of chemical control against pests (Altieri 1994; Altieri and Nicholls 1999; Atkinson and McKinlay 1997; Corey et al. 1993; Meerman et al. 1996; Zadoks 1993). More broadly, it drew attention to the need to preserve the ability of species to adapt in natural areas exploited by man (Altieri and Rosset 1996). From comparisons between natural ecosystems and agroecosystems, a new approach to agricultural problems has gradually emerged, initially with the development of the concept of agroecology in the traditional California school of thought (Altieri 1987; Gliessman 2007): Preserving ecosystems and biodiversity, while reducing pesticide use and fertilizer, became the challenge of agroecology, to ensure that agriculture will be both intensive and environmentally friendly.

Still a young science, a name was proposed in the 1980 s by Altieri (1987) and is still subject to different definitions which clarify its principles, methods, and application (Deguine et al. 2009; Wezel et al. 2009; Wezel and Soldat 2009). According to Dalgaard et al. (2003), agroecology is defined as the study of interactions between plants, animals, humans, and their environment within agricultural systems. As a discipline, agroecology covers many areas within agronomy, ecology, sociology, and economics. For Gliessman (2007), agroecology is the application of ecological concepts and principles to the development and management of agroecosystems while encouraging their conversion to sustainable production systems. Finally, for Altieri and Nicholls (2005), agroecology is primarily the science of natural resource management for poor farmers in fragile environments. It is still the subject of some confusion, probably maintained by rivalries between different 
schools of thought, even though it is recognized as a scientific discipline in its own right (Deguine et al. 2009).

From a methodological standpoint, the management of plant and pest populations highlights three major scientific issues: (i) integration and interdisciplinarity (including ecology, agronomy, crop protection, and socioeconomics) (Dalgaard et al. 2003); (ii) new scales, obtaining local data to be used for large-scale decision making (watershed, district, landscape level, etc.); and (iii) new thresholds at the landscape level (Veres et al. 2013) and long-term solutions (Ryskowski and Jankowiak 2002), taking into account not just economic criteria (classic tolerance thresholds), but also social criteria (shared and accepted decisions) and environmental criteria (environmental care, conservation of biodiversity, reducing the risk of contamination, etc.).

To meet the challenges of ecosystem sustainability advocated in UN international conferences (Stockholm in 1982, Rio de Janeiro in 1992, and Johannesburg in 2002), agroecology has two main driving forces: (i) maintaining or incorporation of plant biodiversity into agroecosystems and (ii) improving the biological activity and the health of soils. These two plans are based on ecological sustainability of natural ecosystems. In the English-speaking world, this agroecosystem management is known as the " $5 \mathrm{M}$ " rule (making, mimics, means, managing, mixtures) (Dupraz 2005; Cardinale et al. 2006), where natural processes are used to develop new techniques, instead of just being copied. These two schemes will provide more innovative and efficient agroecosystem models, supporting productivity and sustainability for both northern and southern hemispheres.

\subsection{The role of biodiversity in agroecosystems}

An ideally functioning agroecosystem requires the provision of various resources or services (supply of food and raw materials, control of diseases and pests, pollination, and regulation of climate) and relies on the diversity of species that coexist and interact (Millennium Ecosystem Assessment 2005). Indeed, species richness or total number of species in a community are positively correlated with the likelihood that they have complimentary spatiotemporal features and functions (Loreau et al. 2001). Biodiversity contributes to the productivity and stability of ecosystems (Yachi and Loreau 1999). Biodiversity also increases the complexity of trophic interactions, which further increase the stability of ecosystem processes and their productivity (Thébault and Loreau 2005).

In cultivated ecosystems, or agroecosystems as defined by Harper (1974), anthropogenic threats are highlighted and alter the benefits provided by biodiversity (Wilson 2002). The establishment of a single cultivated plant species and the use of chemical and energy inputs are causing habitat destruction and pollution (Andow 1983). Agrochemical management of crops has shown its limits: ineffectiveness in controlling pests, altered physicochemical properties of soil, and negative effects on the environment. It therefore becomes necessary to design cropping systems which promote biodiversity, helping to ensure, as in natural ecosystems, the various benefits including increased productivity (Altieri and Nicholls 2004; Costanzo and Bàrberi 2014; Gurr et al. 2003; Isbell et al. 2011; Jarvis et al. 2006; New 2005). Agroecological crop protection meets this challenge, relying primarily on conservation biological control that aims to promote the abundance and diversity of natural enemies of pests and pollinators in agroecosystems and to remove all unfavorable measures (Deguine and Ratnadass 2013; Eilenberg et al. 2001; Nicholls and Altieri 2013). The approach also includes integrated management techniques adapting agricultural practices whose primary purpose is not crop protection, such as tillage, crop rotations, sowing periods and modalities, fertilizer use, and direct sowing techniques (Wezel et al. 2014). It relies on the use of less sensitive or tolerant varieties or mechanical control methods.

Management of ecological composition and diversity in agroecosystems requires, inter alia, consideration of all anthropogenic factors which may play a direct or indirect role (Aviron et al. 2005; Batáry et al. 2012; Clough et al. 2005; Elliott et al. 1998; Norris and Kogan 2005; Weibull et al. 2003; Woodcock et al. 2010). Thompson et al. (2012) emphasize the importance of ecosystem and landscape factors on the diversity of functional groups. These factors include the nature of the species concerned (Holway et al. 2002), the relationship between different trophic levels (Scherber et al. 2010), different types of cropping and phytosanitary practices (Cole et al. 2002; Prieto-Benítez and Méndez 2011), or the effect of landscapes (Bianchi et al. 2006; Tscharntke et al. 2005).

\subsection{Agroecological crop management}

Many authors talk of a succession of paradigms in the evolution of crop protection over a century (Deguine et al. 2008 and 2009; Ehler 2006; Ricci et al. 2011; Sankaram 1999; Thiault et al. 1992; Zadoks 1991). The use of agroecology in crop protection has been discussed since the early 2000 s by Deguine et al. (2009), Ferron and Deguine (2005), Gurr et al. (2004), Landis et al. (2000), and Nicholls and Altieri (2004 and 2007) and is based on several principal axes: (i) enhancement of spatiotemporal plant diversity (known as habitat management); (ii) improving soil quality (organic matter, biological processes), via sustainable farming practices which counter the development of pests; (iii) control of primary inoculation; and (iv) reduction in cultivation intensity. Reducing cultivation intensity aims to minimize the damage where crops and bioaggressors are in contact with each other. This process is via a change in crop status: it increases crop competitiveness and avoids conditions conducive to the development and spread of pests by changing seeding dates and density, 
fertilization methods, irrigation, and implementing species and variety associations. The long-term management of pest populations therefore depends on integrated, concerted, and coherent management of biodiversity and organic matter. This brings together management of soil health and plant health in agroecosystems. In the case of pest management, it seeks to optimize interactions between arthropods (pests, predators, parasitoids, pollinators) and the plant communities (cultivated or not, in or outside the agroecosystem) on which they live (Altieri and Nicholls 2012).

Agroecological insect management is thus based on ecological processes occurring between the crop and its animal pests (Carroll et al. 1990), but also the natural enemies of these pests (Weiner 2003), in a quest for increased beneficial interactions that keep pest populations in check (Altieri and Nicholls 1999; Gliessman 2007). This crop protection strategy helps maintain bioecological balances between animal and plant communities within agroecosystems while also preserving and improving the "health" of soils and plant biodiversity (Ratnadass et al. 2012). Agroecological crop protection is based on prevention at broader spatiotemporal scales. It combines plant and animal community management and thus contributes to conservation biological control (Ferron and Deguine 2005).

Deguine et al. (2009) provide a definition of agroecological crop protection. It is a system of crop protection based on the science of agroecology. By focusing on preventive measures, it aims to establish a bioecological balance between plant and animal communities within an agroecosystem in order to prevent or reduce the risk of infections or outbreaks of pests. Among the conventional techniques used as part of integrated pest management, the focus is on the optimization of cropping practices and of plant population management methods to promote the maintenance or creation of habitats for useful indigenous wildlife and/or counter nuisance flora and fauna. Agroecological protection involves managing plant communities (crops and uncultivated plants in the vicinity of plots as in the agroecosystem as a whole) and animal populations such as pests and various beneficial arthropods (Deguine and Ratnadass 2013). It is known that in diversified agroecosystems, there are fewer general pests (Andow 1991; Vandermeer 1995; Van Emden and Williams 1974) and specialized pests (Andow 1991; Risch et al. 1983) and more auxiliary fauna (Gurr et al. 2004; Landis et al. 2000).

Agroecological crop protection requires concerted action among stakeholders, including farmers and other land managers. Just like integrated pest management, the implementation of curative techniques should only be considered as a last resort and only in case of absolute necessity, subject to implementing techniques which respect functional biological groups, therefore ensuring continuing ecological benefits. The future of pesticides also seems limited, at least in their present state; many of them are already subject to increased restrictions. In this concept, sanitation, habitat management, and conservation biological control are the main components of crop protection and fully regain their relevance and effectiveness.

Based on this agroecological approach, Deguine et al. (2009) propose a phytosanitary strategy adapted to the sustainable management of agroecosystems. In this approach, the essential step, after compliance and regulatory measures and before considering using curative techniques, focuses on the implementation of preventive measures through the management of plant populations (whether cultivated or not) including (i) growing healthy crops and ensuring a healthy soil; sanitation, use of adapted varieties and crop rotation and succession, crop management: direct sowing mulch-based cropping systems with minimum tillage (Scopel et al. 2013), weed management (Gaba et al. 2014), sustainable fertilization and irrigation, and organic amendments; (ii) reducing pest populations and increasing numbers of natural enemies (in the field, its surroundings, the farm and the agroecosystem as a whole); trap plants, management of refuges, associations and intercropping, push-pull techniques, management of borders, construction of ecological compensation structures (corridors, hedges, herbaceous and flower strips, etc.), and techniques for incorporating plant diversity; and (iii) promoting concerted spatiotemporal practices in agroecosystems by neighbor farmers (such as practicing sanitation).

Moreover, contrary to integrated crop protection, agroecological crop protection takes into account different spatiotemporal scales, from local agronomic practices to integration into the landscape, which is close to the area-wide pest management concept (Hardee and Henneberry 2004; Koul et al. 2008; Lindquist 1998; Murray et al. 2005; Vargas et al. 2008) and is closely related to landscape ecology (Burel and Baudry 1999; Sarthou et al. 2014; Turner et al. 2001; Wu and Hobbs 2002). This is one of the reasons that make assessing the effectiveness of agroecological crop protection achievable only by growers and over large areas.

\section{The problem of cucurbit-infesting fruit flies wordwide and in Réunion}

\subsection{Fruit flies in Réunion}

Commonly known as fruit flies, there are about 4448 species of the family Tephritidae (order Diptera) belonging to 484 genera (www.sel.barc.usda.gov/Diptera/tephriti/TephClas. $\mathrm{htm})$. In Réunion, 22 species of fruit flies are present, including four economically detrimental to fruit crops and four harmful to vegetable crops (Etienne 1972; Ryckewaert et al. 2010). These eight pest species belong to the subfamily Dacinae and are divided into two tribes: Dacini and Ceratitidini (De Meyer 2000; White and Elson-Harris 1992). 
There are four species of Ceratitidini on the island: Neoceratitis cyanescens (Bezzi): tomato fruit fly; Ceratitis (Pterandus) rosa (Karsch): Natal fruit fly; Ceratitis (Ceratitis) capitata (Wiedemann): Mediterranean fruit fly; and Ceratitis (Ceratitis) catoirii (Guérin-Merville): Mascarene fruit fly. There are four species of Dacini on the island: Dacus (Didacus) ciliatus (Loew): Ethiopian fruit fly; Dacus (Dacus) demmerezi (Bezzi): Indian Ocean Cucumber fly; Bactrocera (Zeugodacus) cucurbitae (Coquillett): melon fly; and Bactrocera (Bactrocera) zonata (Saunders): peach fruit fly.

The damage caused by fruit flies is extremely detrimental to Réunion; entire crops are frequently lost (Ryckewaert et al. 2010). Female flies lay eggs in fruit which cause their deterioration; larvae feed on the pulp of fruit and other pathogens (bacteria, fungi) may enter egg-laying holes. Consequently, the fruit deteriorates rapidly and falls prematurely (Clarke et al. 2011), making it unsuitable for consumption. Females generally lay eggs in the first few millimeters under the skin of the fruit. The eggs, which are about $1 \mathrm{~mm}$ in size, are white and slightly arched. On hatching, tiny maggots emerge from the eggs. The larvae feed on nutrients such as carbohydrates, protein, and water taken from the environment in which they grow, that is to say, the fruit pulp. Larval development takes place in three stages (White and Elson-Harris 1992), the duration of which varies according to the species and the host fruit (Carey 1984; Fernandes-Da-Silva and Zucoloto 1993). At the end of the third larval stage, the maggot leaves the fruit by jumping to the ground and enters the soil, where it pupates forming a pupa from which the adult then emerges.

In the remainder of this review, the focus will be given to the species which attack vegetable crops, particularly fruit of the Cucurbitaceae family: B. cucurbitae (Fig. 1), D. ciliatus, and D. demmerezi (Brévault and Quilici 2007; Quilici 1994). To distinguish them from other species of Tephritidae, these three species are commonly called "vegetables flies." Through egg laying, vegetable flies inflict considerable damage, causing crop losses as high as $90-100 \%$ despite the application of chemical insecticides (Ryckewaert et al. 2010; Vayssières
1999). These three species of vegetable flies are considered major pests in Réunionese agriculture.

\subsection{Réunion: agriculture, soil, and climate}

Réunion is a volcanic island of $2512 \mathrm{~km}^{2}$ in the southwest Indian Ocean, located at longitude $55^{\circ} 30^{\prime}$ east and latitude $21^{\circ} 25^{\prime}$ south. It is part of the Mascarene Islands, along with Mauritius and Rodrigues (Bertile 1987). Réunion is subject to a humid oceanic tropical climate characterized by an eastern trade wind and high temperatures throughout the year. The annual climate is characterized by two distinct seasons: the austral winter from May to November (rather dry period with mild or cool temperatures in the mountainous areas of the island) and the austral summer from December to April (wet period characterized by high temperatures and punctuated by periodic tropical depressions in the southwest basin of the Indian Ocean). It is important to note that the Réunionese climate is very heavily influenced by the relief of the island and is therefore subject to great variability across the territory. More broadly, we can distinguish the "windward side" to the east, subject to winds and with high rainfall $(>2-3 \mathrm{~m} /$ year) regardless of the season, and the "leeward side" to the west, relatively sheltered from trade winds, where the climate is generally less humid $(<1 \mathrm{~m} /$ year). The volcanic nature of the island and its rugged terrain significantly reduces the area available for agriculture. The utilized agricultural area (UAA) in 2009 was approximately $19 \%$ of the total area of the island, or 47,554 ha, divided into about 7000 farms. Sugarcane is the most common crop in terms of cultivation area $(24,332 \mathrm{ha})$ or $51 \%$ of the UAA in 2009 . It occupies most of the arable nonurban coastal zone. Despite the dominance of the sugarcane industry, other activities including livestock, soilless cultivation, and vegetable crops are experiencing strong growth, due in particular to diversification efforts. In 2009 , vegetable production occupied $5.03 \%$ of the UAA (1585 ha) with 40,500 t produced (approximately $15 \%$ of total farming revenue). This production is greatly reduced by the pressure of pests such as vegetable flies. Crop losses caused by the larvae of these flies can reach $60-90 \%$ in untreated fields (Ryckewaert et al. 2010).
Fig. 1 Females of Bactrocera cucurbitae (a), Dacus ciliatus (b), and Dacus demmerezi (c) (Diptera, Tephritidae) which attack Cucurbitaceae in Réunion (photos: A Franck - CIRAD)
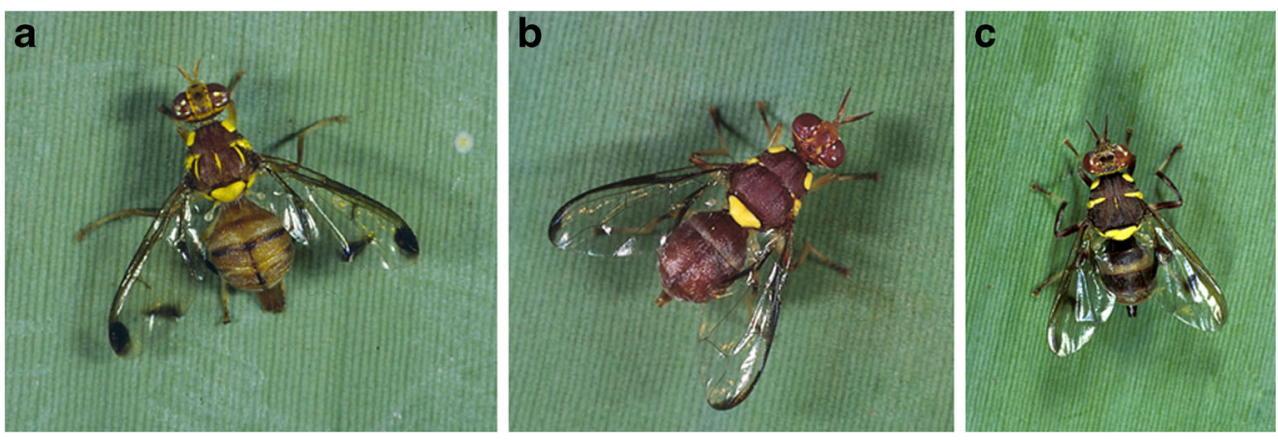


\subsection{Bioecology of the three vegetable fly species}

B. cucurbitae or melon fly was introduced to Réunion from Mauritius. It probably originated from India because of the extensive trade between these two countries (Etienne 1982). The adult is orange in color and has a scutum with three parallel yellow center lines, two large lateral yellow stripes, and two front black macules. The wings have three dark spots. D. ciliatus, the Ethiopian Cucurbitaceae fly, probably originated in Ethiopia where it is widely found (Maher 1957). In Réunion, it was reported in 1964 by Pointel (Etienne 1982). The adult is a red-orange color, with two front black macules and two scutellar bristles. Its wings are transparent with a black costal line that ends with an apical crossband. D. demmerezi, the Indian Ocean Cucurbitaceae fly, originated from Mauritius, where it was described in 1923 by Bezzi (Orian and Moutia 1960). It is also present in Madagascar (Paulian 1953) and Réunion (Etienne 1982). The adult is brown to brown-orange color and has two front black macules, two scutellar bristles, and a yellow lateral line up the back plate to the scutum. The wings are characterized by a high ridge on which sits a diffuse dark spot.

The distribution of adult vegetable flies is influenced mainly by climatic factors, including temperature and altitude, as well as the availability of host plants (Vayssières 1999). B. cucurbitae is present in higher numbers than $D$. demmerezi in the coastal zone, until $600 \mathrm{~m}$. In this area, D. ciliatus coexists with B. cucurbitae. However, upwards of $600 \mathrm{~m}$ altitude, $D$. demmerezi dominates B. cucurbitae, which disappears after $800 \mathrm{~m}$. D. ciliatus can coexist with $D$. demmerezi in an altitude range between 600 and $1200 \mathrm{~m}$. Then, from 1200 to $1500 \mathrm{~m}$, only $D$. demmerezi is present (Vayssières and Carel 1999).

Vegetable flies are active during the day (Vayssières 1999). They rest during the night under the leaves of host plants or other plants. Their daytime activity comes down to finding food, mating, laying eggs, moving around, or resting in a safe place. Some activities are restricted to specific times during the day because of the interaction between the circadian rhythm and abiotic factors such as temperature and light intensity (Fletcher 1987). The main peak of feeding and egglaying activity is usually in the morning for B. cucurbitae (Nishida and Bess 1957; Syed 1969). The activity stops in the evening when light intensity becomes the limiting factor. In these species, mating and food intake take place mainly on nonhost plants (Bateman 1972; Matanmi 1975), which are not involved in either egg or larval development. Detection of the host plant by egg-laying females takes place at a relatively short distance and requires visual and olfactory stimuli. The volatile compounds in fruits are particularly important not only in the location of the fruit, but also in the differentiation between hosts and nonhosts and also for detecting certain phenological stages of the host fruit (Fitt 1986). Sexual activity generally begins at dusk with decreasing light. During this period, the production of sex pheromones has been observed in B. cucurbitae males (Bateman 1972), as well as in D. ciliatus and D. demmerezi males (Dehecq 1995). Lek behavior in males (groups of males and emission of pheromones attracting females for mating) was observed in B. cucurbitae (Kuba and Koyama 1985) as well as in D. ciliatus and D. demmerezi (Dehecq 1995). Most adult Dacini are strong fliers and can travel great distances (Christenson and Foote 1960). Studies have shown that melon fly adults tend to move to the wild vegetation outside the field (Nishida and Bess 1957).

Abiotic factors such as temperature, humidity, and light play an important role on fly abundance. These factors influence directly or indirectly the development rates, mortality, and fertility of the flies (Bateman 1972). For B. cucurbitae, temperatures between 18 and $29^{\circ} \mathrm{C}$ and humidity between 60 and $70 \%$ allow optimum reproduction rates, while lower temperatures reduce survival and reproduction rates (Dhillon et al. 2005; Vargas et al. 2000b).

Vegetable flies, including melon fly, which is the most studied species, are very interesting for their generic characteristics which make them a good study model, from a bioecological and phytosanitary perspective, for other Diptera and pests. Indeed, crop protection against these pests is a major issue and justifies the implementation of numerous control methods.

\subsection{Methods of surveillance and control for vegetable flies}

Whatever the control methods envisaged against these flies, it is important to monitor populations. This allows farmers to know when it is necessary to treat and to verify the effectiveness of the control. For this, there are systems of traps that use a male sex attractant (or parapheromone) specific to males of certain species, Cue-lure ${ }^{\circledR}$. It is only effective on two species of Réunion Cucurbitaceae flies: B. cucurbitae and $D$. demmerezi (Etienne 1982). There are also protein-based food traps like Nulure, Buminal, or torula yeast, which mostly capture females, who need protein for sexual maturation and egg development (Hagen and Finney 1950). In Réunion, the types of traps most commonly used are either liquid attractionbased traps such as the McPhail trap (Trappit Dome Trap, Agrisense, Columbia, MD), or dry traps for sex attractants (supplied as platelets or diffusers) such as the Tephri-Trap ${ }^{\circledR}$ (Ros et al. 1996) or Takamaka ${ }^{\circledR}$.

The establishment of effective control methods against these species is very difficult, especially as the different stages of the life cycle are located at various sites. Eggs and larvae develop in the fruit while the pupae are buried in the ground: most control methods therefore target the adult stage. For optimum efficiency, the procedures must be conducted during the preoviposition period (period of sexual maturation) of the female to prevent damage through egg laying. The most 
common technique used by farmers despite the adverse health and environmental impacts it causes consists of spraying insecticides, such as pyrethroids and organophosphates, during the period of fruit susceptibility. Studies have shown that the organophosphate malathion was the most effective (Jones and Skepper 1965). Currently, it is recognized that cover sprays in general and particularly against Cucurbitaceae flies lead to social, economic, and environmental harm. To minimize these adverse effects, another technique of control consists of a population management by sexual trapping with Cue-lure ${ }^{\mathbb{B}}$ combined with the use of food attractant and insecticide. These different treatments are used to attract and kill adults of both sexes with a parapheromone mixed with an insecticide. The insecticide is applied only on a part of the crop which limits the impact on natural enemies.

Prophylactics are an essential complement in reducing fly populations to below damaging levels. For example, a sanitation method may involve collecting and destroying or isolating all infested fruit that are fly reservoirs (Nishida and Bess 1957). The method of targeting males or "male annihilation technique" (MAT) was developed by Steiner and Lee (1955), and this method attracts and kills using a sexual attractant (Cue-lure $\left.{ }^{\circledR}\right)$ mixed with an insecticide, placed in the same device. Cue-lure ${ }^{\circledR}$ has proven particularly powerful for attracting $B$. cucurbitae males in Hawaii (Vargas et al. 2008). In Réunion, Cue-lure ${ }^{\circledR}$ attracts only B. cucurbitae and D. demmerezi males, so this method cannot be used alone, as it could cause these species to be replaced by $D$. ciliatus. The "sterile insect technique" (SIT) was developed by Knipling (1955). It is based on the rearing, sterilization by ionizing radiation or chemical sterilization, and release of a sufficient number of sterile males to put them in competition with wild males. The ratio of sterile males should be sufficient to decrease the reproductive potential of the target population. This method enabled the successful eradication of B. cucurbitae in various islands of Hawaii (Koyama et al. 2004; Îto and Koyama 1982; Shiga 1989; Steiner and Lee 1955). Biological control of Tephritidae began early in the century: one of the first trials was conducted in Hawaii against B. cucurbitae by Fullaway (1920) through release of Psyttalia fletcheri Silvestri (Braconidae), a larval-pupal parasitoid. To combat D. ciliatus in Mauritius, Moutia (1934) introduced Opius phaeostigma Wilkinson from South Africa. In Réunion, after massive introductions of several species, Etienne (1972) noted very limited settling. P. fletcheri was successfully introduced to Réunion, from Hawaii, in the late 1990s (Quilici et al. 2004).

\subsection{Agroecological crop protection against cucurbit flies}

Before being implemented, agroecological crop protection first requires the following:

- Farmer awareness and enthusiasm, with the aim of achieving significant reductions in pesticide use, to attain integrated, sustainable agriculture (Audemard 2003) and production (Ricci et al. 2011) without impacting on yield, by using other agricultural and plant protection practices and placing farmers in the forefront of the plan

- Addressing the widespread pest problem developing a chemical stalemate; strategic planning, with economic, health or environmental challenges as well as a need for technical research

- Research, development and transfer of knowledge, and a good relationship between research and development partners

- A unifying and structuring project, codesigned by the different groups involved, authorizing the agroecological overhaul of existing cultivation practices and systems and possible innovations at appropriate scales (spatial, time, combined management).

In applying the agroecological approach, we must consider the environment in Réunion and formalize the needs of the various stakeholders (producers and partners in the horticultural industry, research and development, trainers, and technicians). The tropical climate of Réunion usually causes high reproductive rates of insect pests. These insects are part of complex food chains which need to be studied. In addition, these chains are often disrupted by insecticide, which tends to promote pests and disadvantage their natural enemies (predators and parasitoids). Moreover, given the insular nature of Réunion, chronic introduction of exotic pests to the island through imports of plants combined with favorable agroclimatic conditions for their growth and the inability to justify real phytosanitary barriers causes higher insecticide consumption than the national average: $40 \%$ of $480 \mathrm{t}$ of chemicals sold in Réunion in 2009 were insecticides, compared to only $12 \%$ in France (source DAAF Réunion). The adverse effect of the massive use of insecticides is widely acknowledged. It is necessary to promote the establishment or re-establishment of the balance between arthropod communities (Hooper et al. 2005; Fiedler et al. 2008).

To set up agroecological pest protection systems in tropical cropping areas, it is also necessary to acquire a good knowledge of the biology, ecology, and spatiotemporal dynamics of pests which may also be new (via introduction or thriving because of ecological imbalances), which is the case for vegetable flies (Ryckewaert et al. 2010). This will be subject to academic and cognitive research on flies' biology and ecology.

In addition, it is essential to carry out studies to design, develop, and assess agroecological protection techniques targeting pests in Réunion, not only under controlled conditions (laboratory, large cages, behavioral testing stations) but also at producer level, to take account of the specific agroecological requirements at different spatiotemporal scales, from local agronomic practices to integration into the landscape: (i) 
management of spaces (see above); (ii) time management: expansion of spatial scales is consistent with longer time scales in population management. We do not only focus on local information during the crop cycle, but we carry out assessments throughout the year (both growing and nongrowing periods) and over several years; and (iii) collective management: the changing spatiotemporal scale also requires a form of collective management, a shared approach with the stakeholders (mainly producers, but also other players). It is therefore essential that the actors are ready before the new process is implemented.

To this end, a research and development project to assess the feasibility of agroecological protection was designed and launched in 2009. Based on the methods used in Hawaii (Mau et al. 2007), a pioneering project called GAMOUR was designed with the purpose of solving this problem, contributing to the development of a sustainable, healthy, and productive agriculture in Réunion (Augusseau et al. 2011). The project consists of two main approaches: (i) the development and adoption of agroecological crop protection and (ii) raising stakeholders' awareness of sustainable agriculture. Project GAMOUR relied on an agroecological approach to both improve both soil health and to increase plant biodiversity in agroecosystems. GAMOUR brought together 14 local and national organizations with different tasks but the same goal. These partners included Réunion Association for the Modernization of Horticulture, Fruit and Vegetable Farming (ARMEFLHOR); the Chamber of Agriculture of Réunion; Centre for International Cooperation in Agronomic Research for Development (CIRAD); Departmental Federation for Protection against Harmful Organisms in Réunion (FDGDON); Farming and Environment Forum (FARRE Réunion); and Réunion Organic Agriculture Association (GAB). The project was implemented in three villages (Entre-Deux, Petite Ile, and Salazie) covering about 50 ha and involving 30 farmers, including four certified organic farms (Fig. 2), with the objective of evaluating the techniques and to measure farmer satisfaction. Study methods consisted of (i) experiments in the field, (ii) monitoring of fly populations at the sites, (iii) monitoring of farms and fields, and (iv) a survey of the farmers involved. More is available on http:// gamour.cirad.fr.

\section{Results on the bioecology of cucurbit flies}

\subsection{Transition to southern winter}

A reduction in vegetable fly populations and damage to vegetables is observed during the southern winter in Réunion (Vayssières 1999). Under natural conditions, Vayssières and Carel (1999) note that the altitudinal distribution of flies changes during the year and there is a partial withdrawal of
Dacini populations on the coast (where temperatures are highest). Although Dhillon et al. (2005) observed that during the coldest winter months, B. cucurbitae adults take refuge in the dried leaves of bushes or trees, we do not know what causes these decreases in fly populations during the winter. Such knowledge would enable better population management at the onset of infestation and thereby establish a more effective crop protection. Indeed, it has been shown in Hawaii that the management of fly populations at the onset of infestation reduces damage to fruit (Vargas et al. 2008).

The two hypotheses to explain fly population decreases in winter involve individuals remaining in place, in a state of diapause or dormancy, or migration to more favorable higher temperature areas. In order to discern which hypotheses is correct, three techniques were used on five vegetable farms selected in various climatic zones: trapping, sampling of infested fruit, and soil sampling (Deguine et al. 2012a). The results of trapping and fruit sampling show changes in fly populations during the year, especially during the winter, during which they reach a minimum. At lower altitudes, the numbers remain relatively low during the winter. The hypothesis of migration is therefore not one we would favor, although in experiments, it has been shown that some species travel considerable distances before finding a suitable host (Drew and Hooper 1983). B. cucurbitae can travel up to $200 \mathrm{~km}$ (Miyahara and Kawai 1979). However, considering that most Dacini spend winter in their adult form (Fletcher 1987) and that in Hawaii it has been shown that at $15{ }^{\circ} \mathrm{C}$ $B$. cucurbitae adults remain inactive under foliage (Nishida and Bess 1957), the assumption that these populations spend the winter in a dormant state seems most likely (Deguine et al. 2012a).

\subsection{Population changes during the southern summer}

For a long time, the study of the biology and ecology of Cucurbitaceae flies has essentially relied on two techniques (Quilici 1994). The first technique, adult trapping, uses Cuelure $^{\circledR}$, a sexual parapheromone. This technique presents limitations for bioecological study of communities: this attractant is effective only on two of the three species (D. ciliatus is not attracted) and only males are trapped. The second technique is to collect fruit on the ground, whether infested or not, to bring them back to the laboratory for incubation in order to obtain pupae and adults (Vayssières 1999). However, development of fruit flies in different species of Cucurbitaceae is variable and does not necessarily reflect the in situ fly population. For example, only $D$. ciliatus develops in chayote fruits (Deguine et al. 2013). Furthermore, studies confirm that adults often land outside Cucurbitaceae plots and can be found easily on plants situated flanking the crop. Of these plants, maize has proven to be the most attractive plant in Réunion (Atiama- 


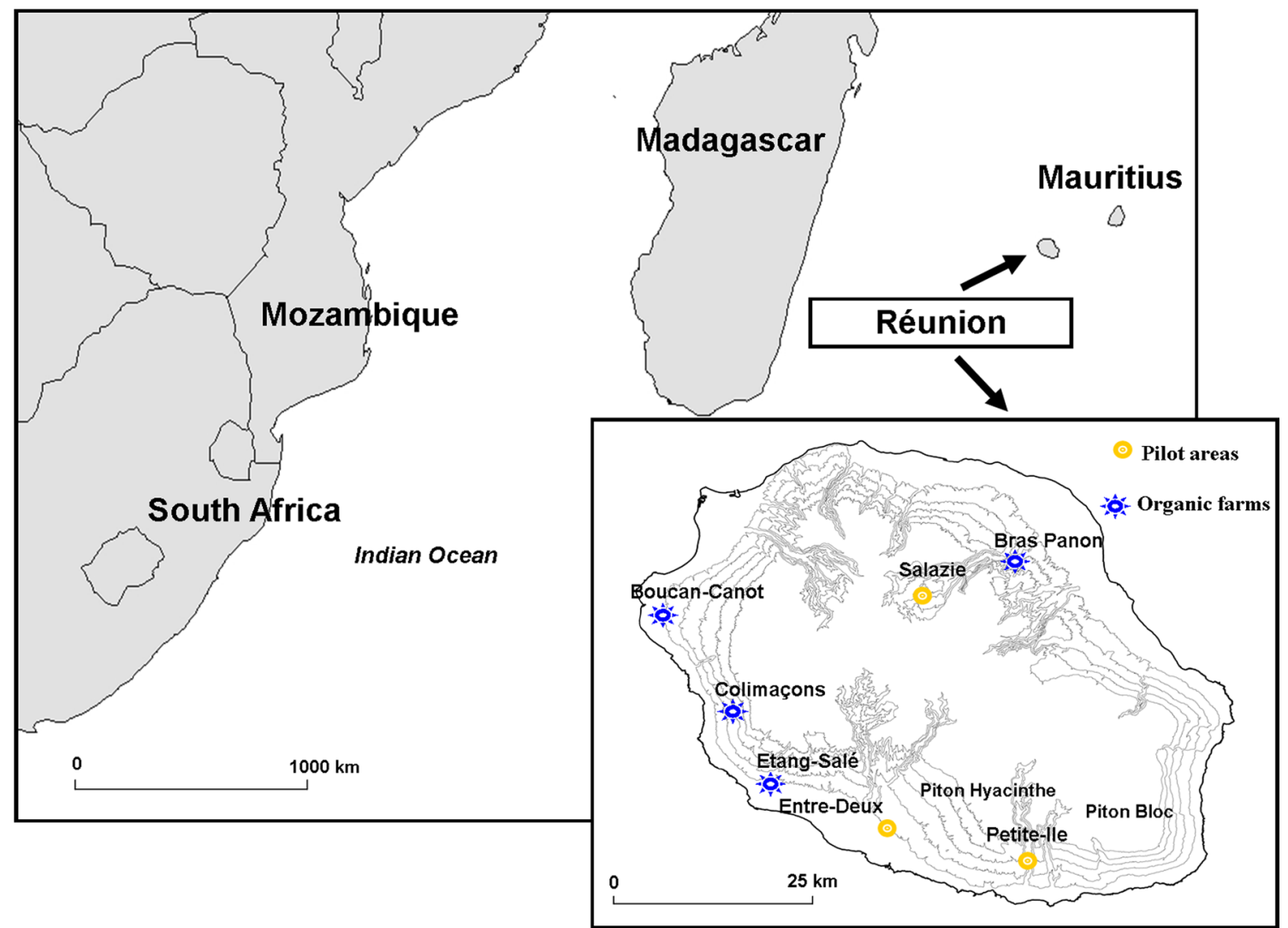

Fig. 2 Pilot areas and organic farms of GAMOUR project in Réunion

Nurbel et al. 2012), confirming results from Hawaii (McQuate et al. 2003). Thus, to overcome the mentioned limitations, we developed a visual inspection technique to observe adult vegetable fly populations. It was designed for different crops from 2008 to 2010 (Deguine et al. 2012b) and consists of counting species and sex of flies on plants grown in the field and on maize plants placed on the edge of the field or within the cultivated plot. The technique is suitable for communities where three species of fly coexist. Seasonal fluctuations, relative abundance, and sex ratios of the three species can be studied.

With visual counting on maize, we studied population changes and certain characteristics of vegetable fly communities by counting the number of adults in the field borders. Several features were observed: seasonal population fluctuations, relative abundance of different species, and sex ratios. The study was conducted over 3 years during the austral summer (between January to April), when Cucurbitaceae flies are present in highest numbers. Counting took place in a range of altitudes (750-1150 m) corresponding to the main areas of Cucurbitaceae cultivation in Réunion (Deguine et al. 2012b). In total, this study consisted of $147 \mathrm{~h}$ of observation and 18 , 441 flies were counted.

The results showed a great variability in the seasonal fluctuation of populations based on local conditions (Fig. 3). In addition, the relative abundance of $B$. cucurbitae is low $(<18 \%)$ for sites at higher altitudes (above $1000 \mathrm{~m}$ ), where $D$. demmerezi is the most common species ( $>56 \%$ ) (Deguine et al. 2012b). The relative abundance of $D$. ciliatus varies depending on the situation; it is the dominant species in pumpkin crops (54\%). Depending on location and species, the sex ratio varied from 1:1 to 1:2, females/males (Fig. 4).

The variability in relative abundance and sex ratio is due to the large-scale cumulative factors and local effects at plot and plant levels. These effects are abiotic (altitude and climatic conditions including temperature, rainfall, and relative humidity) and biotic (host type, intra- and interspecific competition, predation and parasitism, etc.).

\subsection{Circadian rhythms and activities of flies within the crop}

Although maize is not a host plant, in situ observations reveal that the three species (B. cucurbitae, D. ciliatus, and $D$. demmerezi) spend most of their time on maize. Hourly counts (from 7:00 to 19:00) give, regardless of the day, the following results (Atiama-Nurbel et al. 2013): (i) almost all flies can be found throughout the day on the maize borders of and population levels on the zucchini are low or almost zero, with the exception of a few hours per day, depending on the species; and (ii) while the males remain in borders all day, 
Piton Bloc, 2008 (1,000m)

Density of adulis (per $\left.10 \mathrm{~m}^{2}\right)$

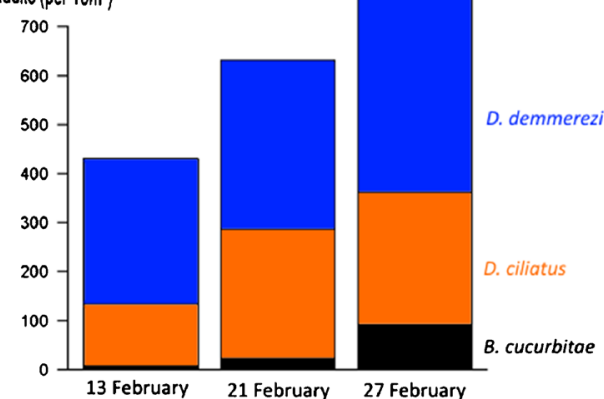

Densily of adults (per $\left.10 \mathrm{~m}^{2}\right)$

Tan Rouge, 2009 (750m)

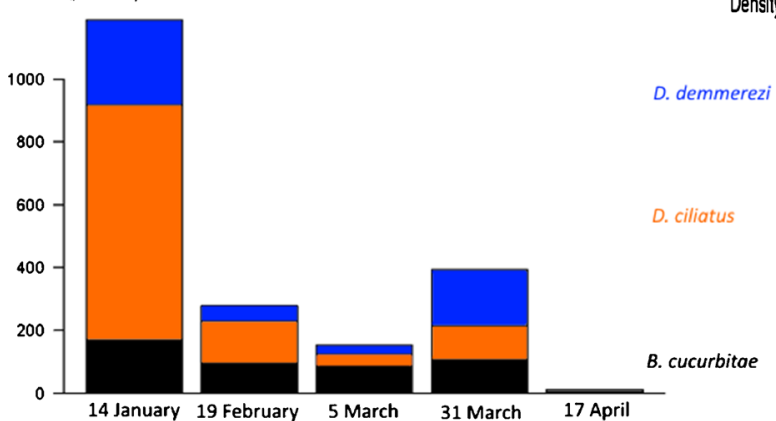

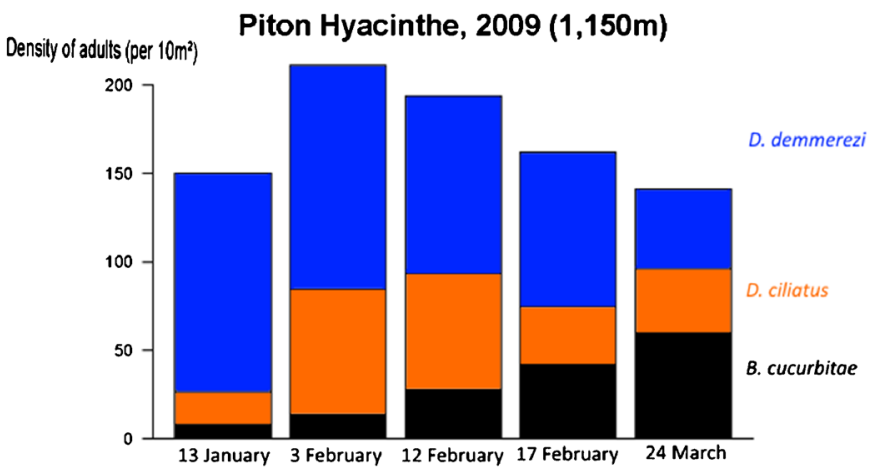

Tan Rouge, 2010 (750m)

Density of adults (per $\left.10 \mathrm{~m}^{2}\right)$

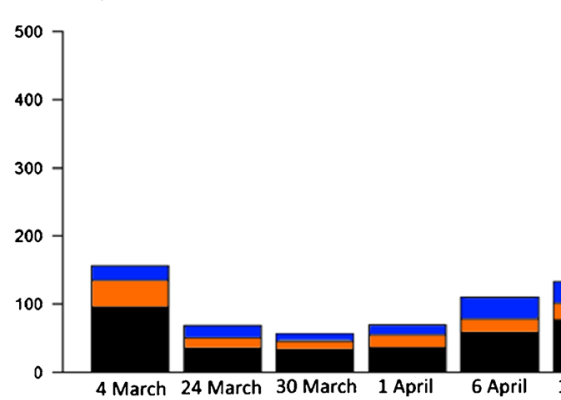

D. demmerezi

D. ciliatus

B. cucurbitae

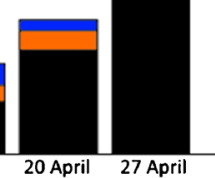

Fig. 3 Seasonal fluctuation of the structure of adult flies community (Bactrocera cucurbitae, Dacus ciliatus, and Dacus demmerezi) (density per $10 \mathrm{~m}^{2}$ of corn per date) in four agroecosystems from 2008 to 2010 (in Deguine et al. 2012b)

only gravid females migrate to the zucchini to lay eggs (Fig. 5).

On maize, flies essentially "roost". Adults shelter, rest, travel, walk, protect themselves (against their natural enemies and adverse weather conditions such as intense sunlight or heavy rainfall), and feed (their diet is based on honeydew, nectar, maize exudates, bird droppings, or leaf pathogens) on these "roosting sites". This is the chief activity for all species:
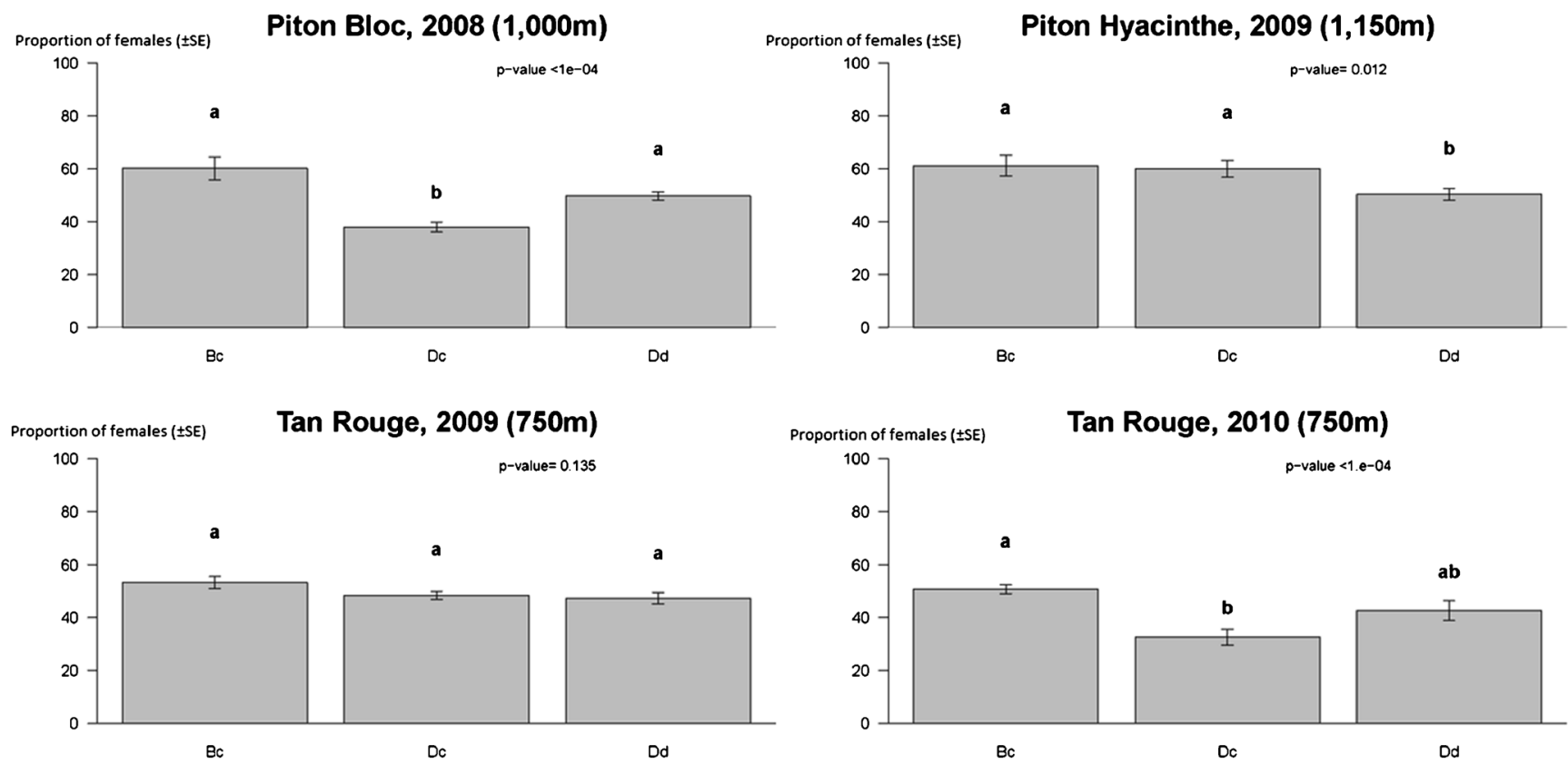

Fig. 4 Sex ratio of Bactrocera cucurbitae (Bc), Dacus ciliatus (Dc), and Dacus demmerezi $(D d)$ in four agroecosystems from 2008 and 2010. Tests with general linear model (with $p<0.05$ ) were done separately for each situation on the adult flies density (per $10 \mathrm{~m}^{2}$ of corn) which are

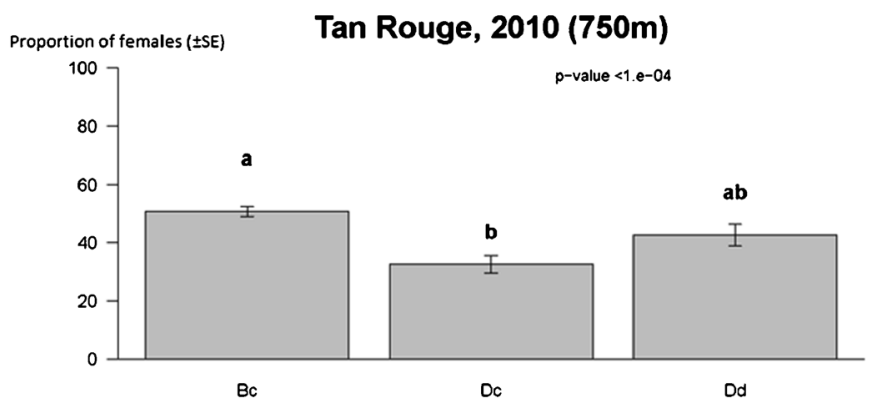

given (date was considered as a replication). Standard errors and $p$ values are given for each situation. Sex ratios not followed by the same letter in a range are significantly different (in Deguine et al. 2012b) 
Fig. 5 Day evolution of female (red) and male (green) number of Dacus demmerezi observed on a zucchini crop (Piton Hyacinthe, 3 February 2009). First, females were searched and oviposition sites selected, and after this period, a peak of oviposition occurs

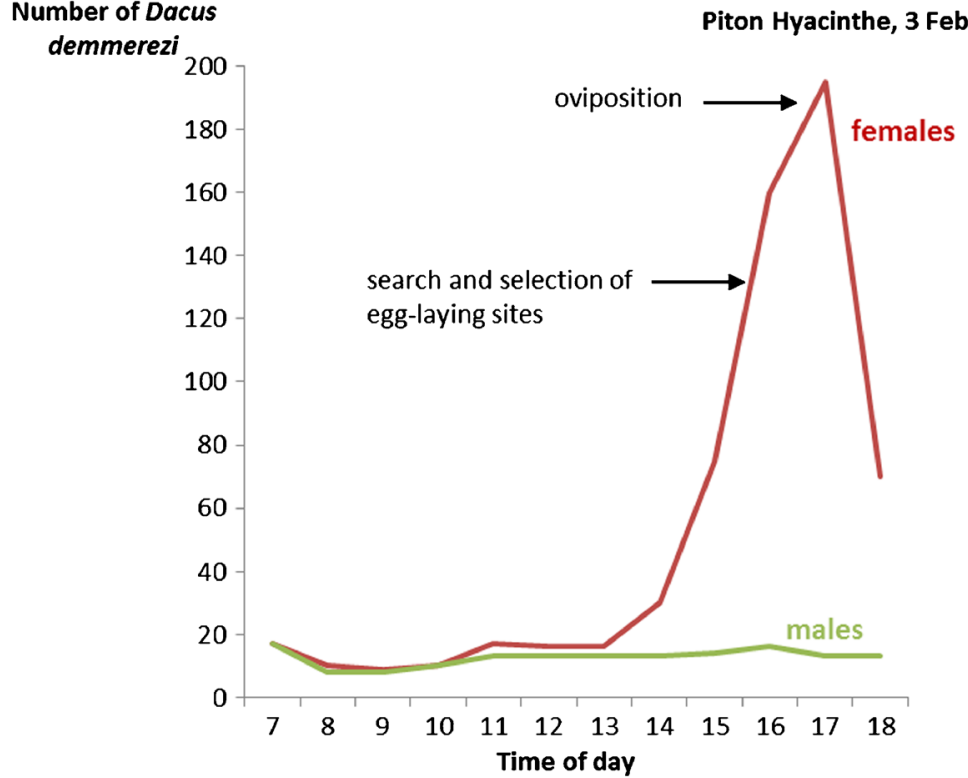

$93 \%$ of the 3646 adults observed in 2008, $99 \%$ of the 5749 adults observed in 2009, and $96 \%$ of the 7227 observed in 2010 , averaging more than $95 \%$ of the 16,622 adults counted (Deguine et al. 2012b). In addition, certain reproductive activities, such as leks and coupling, take place on the maize. Leks, groups of males attracting females to mate, are mainly observed on maize leaves and start for three species around 17:00, depending on the photoperiod and light intensity. Mating usually takes place at night after the lek, sometimes until dawn.

Hourly observations show that three species of vegetable flies have circadian rhythms, as has been shown for the tomato fly N. cyanescens (Brévault and Quilici 2007 and 2009). The rhythms vary between the three species. These circadian rhythms are mainly related to the movement of females between maize and zucchini, and gravid females leave the maize to lay eggs on the zucchini.

Typically, females are found on cultivated fruits, with the males remaining on the maize. After a searching for a suitable laying site, the female lays her eggs on the fruit. Time of laying varies between species and observations conducted over 3 years show the following trends: females of B. cucurbitae lay eggs between 10:00 and 15:00, D. ciliatus between 10:00 and 13:00, and D. demmerezi from 16:00 to 19:00 (Atiama-Nurbel et al. 2013).

\subsection{Sechium edule}

Chayote ( $S$. edule) is a very popular plant in Réunion. Traditionally grown in the wild for its leaves, it is also grown under trellises for its fruit. Many fruits fall to the ground, representing a significant loss of production. Farmers tend to attribute these losses to three species of cucurbit flies. This has caused substantial spraying of insecticide on the trellises although the actual numbers of flies have never been assessed.

Experiments were conducted in 2008 and 2009 in chayote trellises located at various locations on the island. In 2008, hundreds of fruits were collected at a single site to assess the vulnerability of the fruit. At the same time, we followed the growth of 20 recently infested fruit in the field. Over 120 fruits were collected in 2008 from two sites, and 20 fruits were collected weekly in 2009 from one site. All these fruits were brought to the laboratory where fly development was monitored for 15 days (until adult emergence). We also placed antibird nets in three fields of chayote in 2009 to collect falling fruits before they hit the ground. These fruits were brought to the laboratory in order to count the number of egg holes and infestation level. Finally, in the laboratory, we exposed chayotes to gravid females (eight per female). These chayotes were then dissected and the egg-laying sites examined.

In the field, fruits less than $6 \mathrm{~cm}$ long do not seem affected by oviposition by females. Two to 4 weeks after being infested, these fruits do not show any difference compared to noninfested fruits. These results are reinforced by the emergence tests. Only 1 of the 120 fruit collected in 2008 and 5 of the 219 collected in 2009 showed signs of emergence. D. ciliatus seems to be the only fly capable of growing on chayote, not only in fruits collected from the field but also in those artificially infested in the laboratory. During the dissection of infested fruits, we observed a "defensive reaction" against the eggs and B. cucurbitae and D. demmerezi L1 larvae. Finally, nets collecting the falling fruit showed that over $90 \%$ of these fruits were not infested with fly eggs.

This study shows, for the first time, the real impact of vegetable flies on chayotes grown in Réunion: Although flies are present in the trellises, these pests are not responsible for 
the significant losses suffered by farmers (Deguine et al. 2013). This suggests that the chemical protection used against flies is not appropriate, especially considering the negative effects of these treatments. The physiological stress of overloaded trellises, caused by intensive cultivation, could be the main cause of fruit loss and requires further research.

The main areas of research on vegetable flies and chayote are as follows: testing the hypothesis of physiological stress as the main cause of fruit loss; studying interactions between crop management and production, as defined by Aubertot and Robin (2013) on the physiological state of the chayote; examining varietal effects; studying the reaction of the fruit to infestation; and finally measuring the reduction in fly populations using the GAMOUR technical package.

\section{Relevance of agroecological population management techniques}

\subsection{The augmentorium as a sanitation tool}

A special sanitation technique was first developed in Hawaii (Liquido 1991, 1993), using a tool called an augmentorium (Jang et al. 2007; Klungness et al. 2005). This is a closed tentlike structure with a roof consisting of mesh. Set up next to the crop, the structure is used by the farmers who place infested fruit inside. Adult flies emerging from the fruits are locked inside and eventually die. On the other hand, the mesh allows the smaller parasitoids to escape, especially the two braconid species Fopius arisanus (Sonan) and P. fletcheri (Silvestri), parasitoids of, respectively, B. zonata and B. cucurbitae. We conceived, developed, and evaluated the performances of an augmentorium specifically adapted to the conditions in Réunion (Fig. 6).
In 2009, a survey was carried out in Entre-Deux, a small village in the south of Réunion with a strong horticulture industry (fruits and vegetables) (Deguine et al. 2011). The fruit and vegetable fly problem was well known there not only by farmers but also by private garden owners. The survey included 30 farmers and 90 inhabitants. Twenty-five of the 30 farmers interviewed, growing Cucurbitaceae or Solanaceae, were affected by vegetable insects. They estimated their losses to be more than $40 \%$, sometimes as high as $80 \%$ for seven of them. Seventy percent of the private garden owners also experienced significant losses due to the flies. Meanwhile, $70 \%$ of farmers and $53 \%$ of private owners agreed that chemical insecticides (pyrethroids and organophosphates) were ineffective against flies. Nevertheless, $100 \%$ of the farmers did spray their crop once to twice a week. Both farmers and private owners used alternative techniques such as the male annihilation technique using Cue-lure (60\% of farmers). On the other hand, sanitation was not practiced. Farmers considered it oldfashioned and private owners were not aware of it. Ninety percent of farmers said that they would adopt a new methodology if proven effective. Thus, $83 \%$ of farmers and $84 \%$ of private owners stated that they were ready to use an augmentorium.

To make the Hawaiian models usable in Réunion, they needed to be adapted to local flies and parasitoids. The work started in 2008 and initially focused on the mesh size to be used in the augmentorium. This is a key factor in terms of fly sequestration and parasitoid augmentation. Trials were carried out in the laboratory at CIRAD in Réunion. Four mesh types, including the one used in Hawaii, were tested in laboratory conditions. During the laboratory tests, one of the meshes tested was found to be adapted to all flies and parasitoids in Réunion. Even with large amounts of insects, this mesh retained all the tested flies (C. capitata, the smaller one;
Fig. 6 Sanitation using augmentorium technique (photos: JP Deguine-CIRAD). a An augmentorium in a zucchini crop. b Some infested zucchini thrown into an augmentorium. $\mathbf{c}$ Net on the top of the augmentorium. $\mathbf{d}$ Adult flies sequestered by the net inside the augmentorium

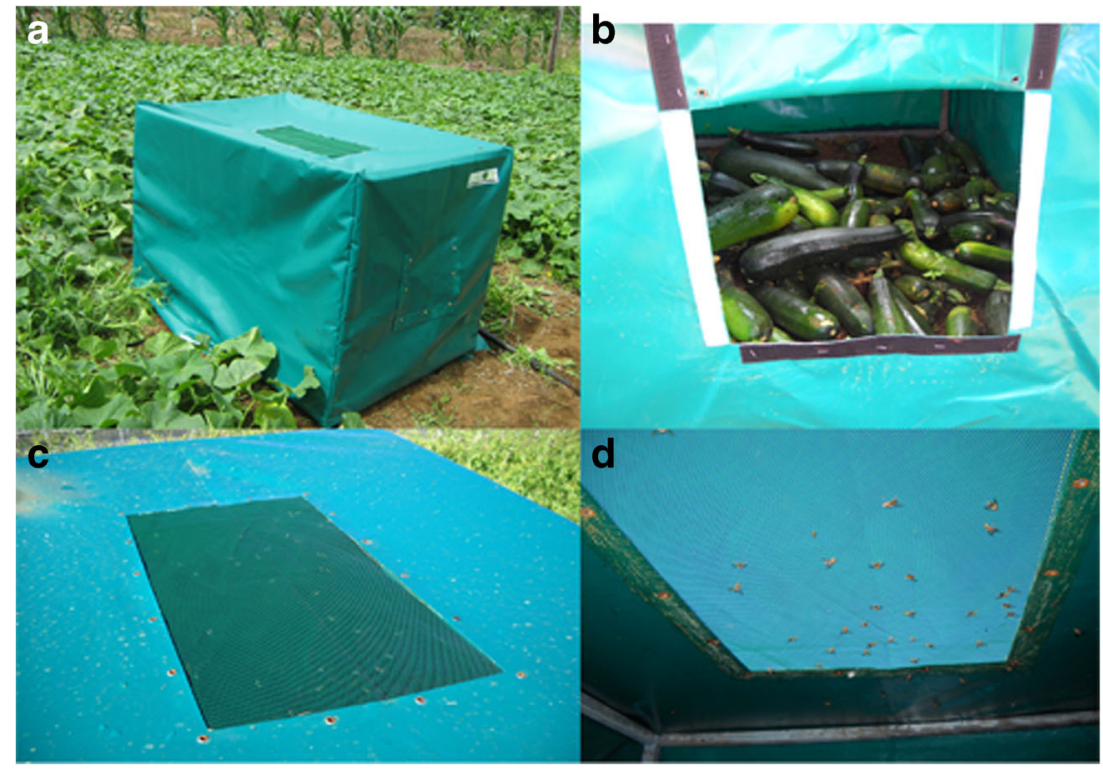


B. cucurbitae; and B. zonata). Furthermore, both parasitoids could pass through the mesh (mean rates of escape 68 and $98 \%$ for $P$. fletcheri and $F$. arisanus, respectively).

In addition, we conducted interview-based surveys to collect information for the development of a new Réunion augmentorium (Deguine et al. 2011). Seven organic farmers gave feedback before, during, and after a 1-year trial of the augmentorium. Two types of augmentoria were provided to several dozen farmers in 2009 and 2010. Their feedback was collected in order to shed light on the success of the technique. Discussions with farmers allowed the development of a first augmentorium matching the requirements of organic farming. Several major drawbacks were pinpointed, particularly the cloth which was found to be too fragile for severe climatic conditions. Two other models were subsequently developed, which are currently built and sold by a local Réunion company (Takamaka Industries). Improvements could still be made to the augmentorium's use in the field. Frequency of collection is closely linked to crop type: daily collection appears necessary for zucchini, though one or two collections per week are sufficient for chayote. A minimum delay of 1 month after the last drop is required before opening the augmentorium (average life cycle duration of cucurbit flies), but a longer delay of 5 to 6 weeks is more prudent. Thus, the alternate use of two augmentoria per field was recommended.

From 2009 to 2011, 81 augmentoria consisting of two different models were delivered to conventional and organic farmers. The outcome was largely positive: all of them were satisfied. The effectiveness of the technique was assessed by quantifying sequestrated flies and by a significant increase in yield. Moreover, less manpower time was needed for fruit collection as compared to traditional chemical spraying.

Sanitation using an augmentorium may be the most efficient component of agroecological protection against fruit flies. It could also be considered as a potential tool for biocontrol because it releases parasitoids, decreases fly populations, and produces compost (Kehrli et al. 2004). Finally, taking into account the positive feedback from farmers, this technique could allow the partial or total suppression of chemicals for both crops and private gardens.

Finally, the augmentorium produces compost by mixing decomposing fruit with a suitable amount of organic matter. Initial tests of infested zucchini mixed with residues of sugarcane stalks and poultry litter waste showed potential. This technique is not just limited to cucurbit producers; it can be used for the protection of crops in many other situations. Potential users are numerous, from amateur gardeners to farmers.

\subsection{Insertion of trap plants in the agroecosystem}

Nishida and Bess (1957) studied the circadian rhythm of B. cucurbitae in Hawaii and highlighted the daily movements of insects between crops and their immediate surroundings (border plants and nonhosts). In Réunion, a large cage-based behavioral study focused on the attractiveness of trap plants for two species of Cucurbitaceae flies: B. cucurbitae and D. demmerezi (Atiama-Nurbel et al. 2012). Two plant species in the family of Poaceae were chosen: maize (Zea mays L.), one of the most attractive plants for insects, used as a trap crop for B. cucurbitae in Hawaii; and fodder cane (Pennisetum purpureum Schumach) (McQuate et al. 2003; McQuate and Vargas, 2007), the most common noncommercial trap plants in Réunion. Both candidate plants were placed in pots and arranged in prime position in large behavioral cages $(2.5 \mathrm{~m}$ in height by $3 \mathrm{~m}$ in diameter) placed outdoors. Four states were defined based on the sex and the age of flies: immature male, mature male, immature female, and mature female. In each cage, a cohort consisting of 100 adults (50 $q$ and 50 ऽ) of known state was released. For each case, the experiment was repeated four times. The number of flies on different plants and their location on the plant were recorded. For adults of both species, maize is significantly more attractive than fodder cane (Fig. 7). The majority of adults of both species were found on the maize and fodder cane leaves. Date, time of day, age, and sex of the flies do not change the general attraction trend. These results allowed us to select maize as trap crop for use on farms in Réunion.

The attractiveness of maize was confirmed in situ in various tests set up over several years (Atiama-Nurbel et al. 2013). Maize is attractive to all three species, B. cucurbitae, $D$. ciliatus, and D. demmerezi; high densities of flies were found in each study (167-607 flies per $10 \mathrm{~m}^{2}$ maize). As an illustration, of 7285 adults counted on maize and zucchini in Tan Rouge in 2010, over 99 \% were observed on maize. For similar observation times and areas, the ratio of numbers of adult flies on zucchini and maize was 1:1000 in Piton Bloc in 2008. In addition, several maize planting strategies were compared: crop borders (Fig. 8) and patches or strips within the crops. They are equally effective (Atiama-Nurbel et al. 2013).

The planting of maize is not limited to trapping flies and managing fly populations. We already know that planting maize in agroecosystems allows fly populations and communities to be assessed: in situ counting on maize makes it possible to obtain an accurate estimation of the fly populations present in the agroecosystem unlike conventional methods of sexual trapping using pheromones or studying fruits collected in the field. It is thus possible to quantify certain population characteristics such as relative abundance or sex ratio between different species of flies.

Maize also attracts other arthropods, in particular useful insects, e.g., hoverflies, which are pollinators, predators, and reliable indicators of a healthy agroecosystem. A 2010 study found that the planting of maize attracts significant numbers of three species of hoverflies: Allograpta nasuta (Macquart), 


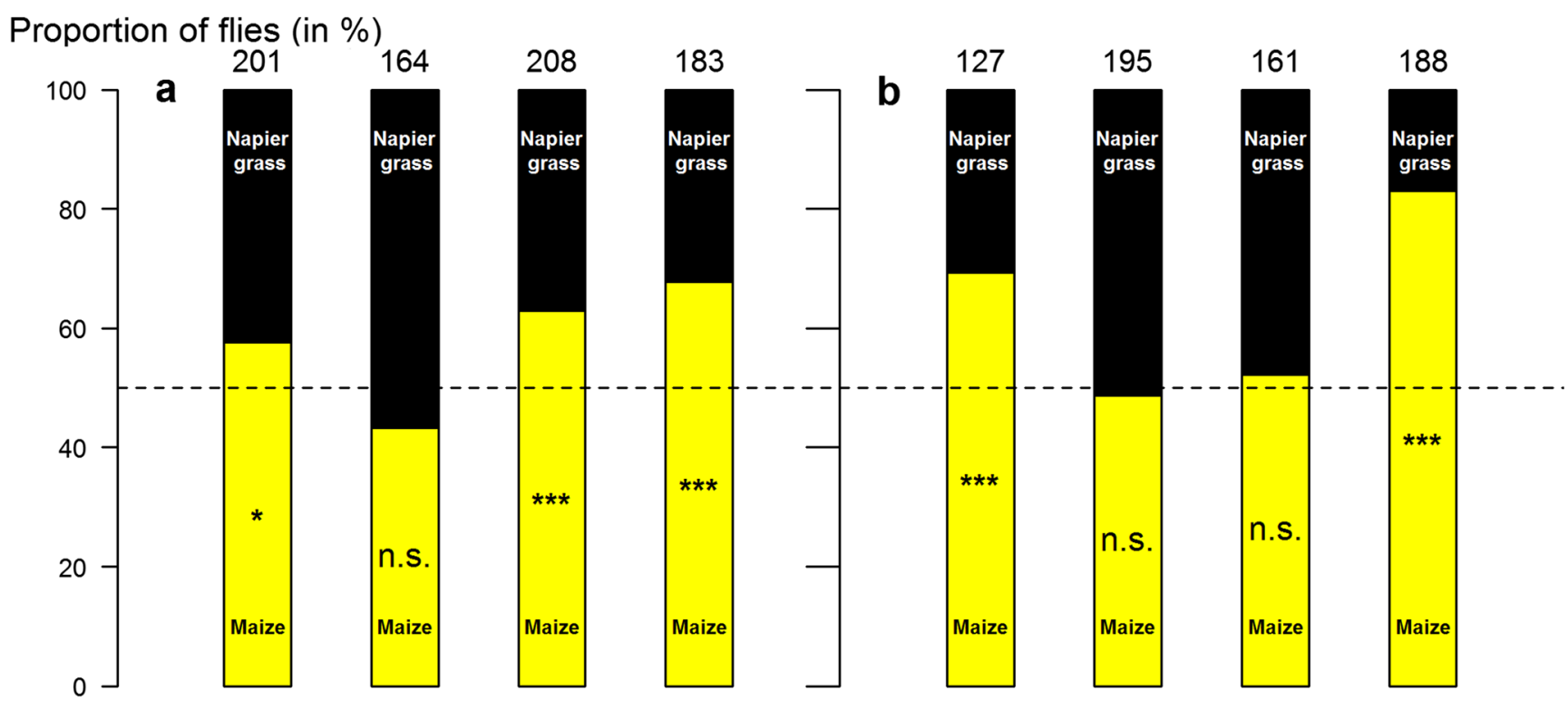

Proportion of flies (in \%)

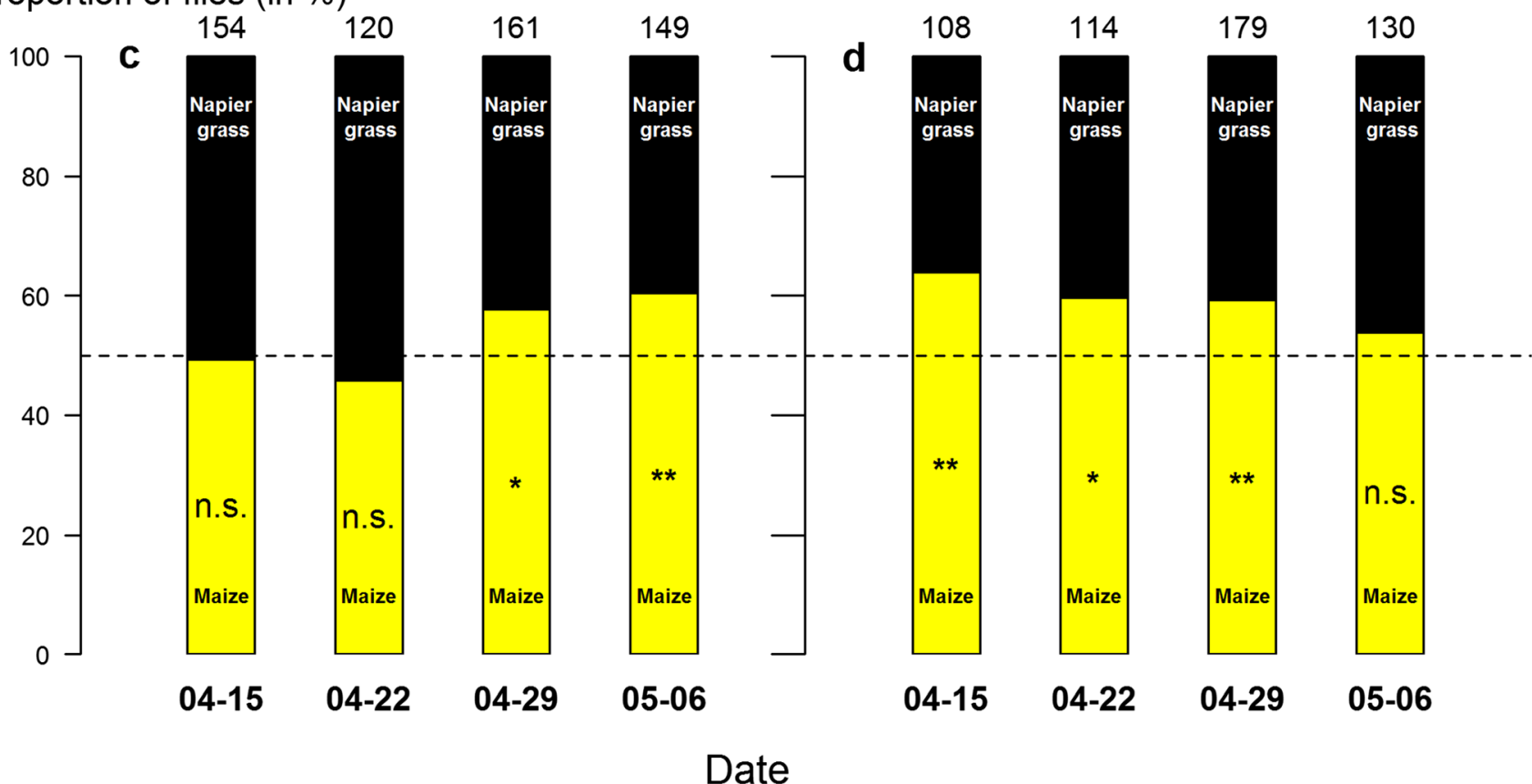

Fig. 7 Proportion of adult Bactrocera cucurbitae observed on maize (Zea mays) and Napier grass (Pennisetum purpureum) for each observation date and for each state of the flies (Saint-Pierre, field cage

Episyrphus circularis (Hull), and Melanostoma annulipes (Macquart) (Duhautois 2010). M. annulipes reveals a peak pollinating activity at 8:30 am which corresponds to the period of maximum pollen release. Populations of pollinating insects (especially bees) are also found in large numbers in Cucurbitaceae plots when maize is placed in the agroecosystem.

Farmers appreciated maize as a trap plant firstly because it provides a border for a restricted period of time, as opposed to a perennial border. Also, using maize as a border plant had the potential for another crop to be harvested in the cropping tests, 2008) (in Atiama-Nurbel et al. 2012). a Immature female, b immature male, $\mathbf{c}$ mature female, $\mathbf{d}$ mature male

system. Thirdly, maize was very well adapted to the pedoclimatic conditions.

\subsection{Application of insecticide bait on trap plants}

To prevent females from laying eggs on crops when a large number of vegetable flies are present on trap plants, an insecticide bait is used on the trap plants, as practiced around the world on some Tephritidae (Burns et al. 2001; Köppler et al. 2008; KunYaw et al. 2005; Piñero et al. 2009a; Prokopy et al. 2004). Our studies have attempted to measure, using three species of 


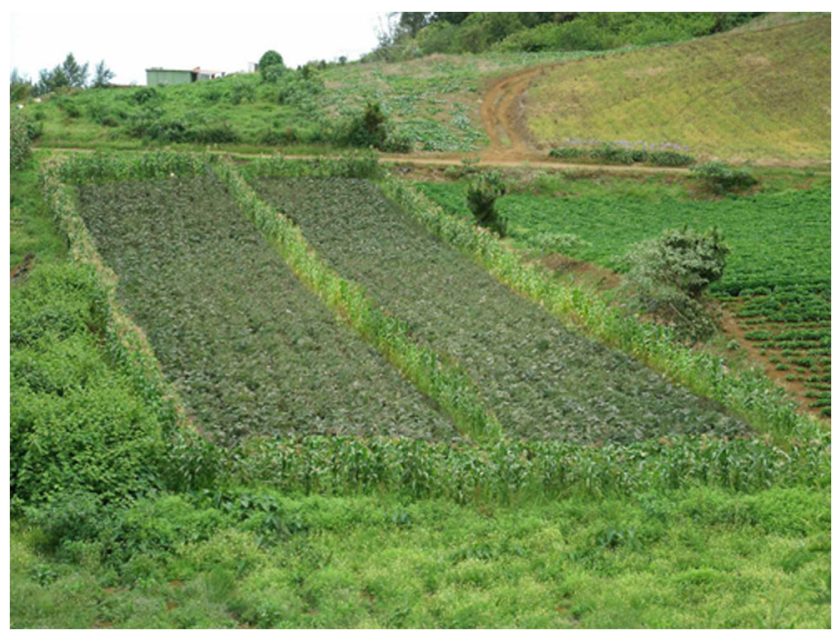

Fig. 8 Trap corn plants bordering zucchini crop in a pilot area of GAMOUR project in Réunion (photo: JP Deguine - CIRAD)

vegetable fly, the efficacy of Synéis-appât ${ }^{\circledR}$ (available in France), composed of $99.98 \%$ protein attractant and $0.02 \%$ spinosad, an insecticide approved for organic farming. In Réunion, testing in large cages showed that at a dose of $1: 5$, the product is effective against $B$. cucurbitae ( $94.6 \pm 0.7 \%$ mortality) and $D$. demmerezi $(85.7 \pm 2.1 \%)$ and moderately effective against $D$. ciliatus $(60.4 \pm$ $4.4 \%$ ) (Deguine et al. 2012c). No sex effect was observed for each species. The mortality response of $D$. ciliatus was slower relative to the other two species.

The effectiveness of Synéis-appât ${ }^{\circledR}$ on three species of Cucurbitaceae flies was also analyzed in field trials over 3 years $(2009,2010$, and 2011) (Delpoux and Deguine 2015). The results are consistent: the product is very effective against $B$. cucurbitae, good against $D$. demmerezi, but only mediocre against $D$. ciliatus. The mortality response of D. ciliatus is also slower relative to the other two species.

In general, fly numbers in the first few hours following treatment follow the same trend: an increase in the first $3 \mathrm{~h}$ followed by a gradual decrease over time. We therefore

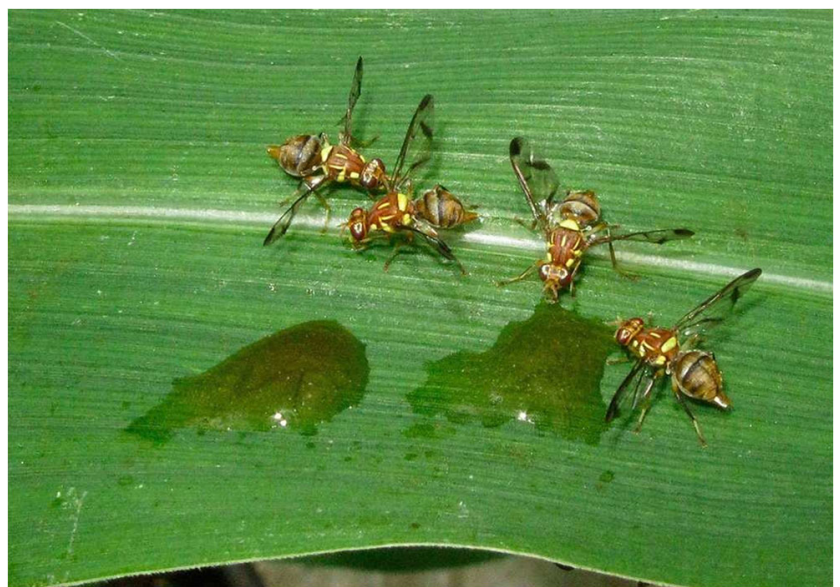

Fig. 9 Bactrocera cucurbitae females feeding on Synéis-appât ${ }^{\circledR}$ bait sprays (photo: A Franck-CIRAD) conclude that the action of the product is not limited to the borders on which it is applied, but reaches surrounding host plants. Three phases occur after application of Synéis-appât ${ }^{\circledR}$ :

- A short-term positive effect (several hours after application)

- A short-term insecticidal effect (a few hours after application)

- A medium-term insecticidal effect (a few days after application)

Synéis-appât ${ }^{\circledR}$ is spread in a localized manner (every $10 \mathrm{~m}$ ) by spotting a few drops on trap plants (maize) planted around the edges of the field. Flies in the vicinity are attracted by the spots and ingest the bait, causing their death (the insecticidal effect) (Fig. 9). However, this technique was not suitable for zones with heavy rainfall (due to product leaching). We therefore developed a method of protecting the product from precipitation.

A Synéis-appât ${ }^{\circledR}$ application system adapted to the climate of Réunion was compared with a control system made in Taiwan (yellow umbrella) (Piñero et al. 2009b) and developed from local materials (Delpoux and Deguine 2015). The color was chosen after a comparative study: yellow attracts more flies than white, red, or transparent materials. The device, a horizontal yellow bottle cut in half and impregnated with insecticide (spinosad) on the lower surface, can be used on Cucurbitaceae (placed around the maize edges) and under chayote trellises. This protects the Synéis-appât ${ }^{\circledR}$ from rain. In field trials (three locations over 2 years), the number of flies was counted on the two types of devices over 3 days. Success was measured by the number of flies coming into contact with the insecticide. Altogether, the yellow umbrella attracted as many fruit and vegetable flies (520) as the horizontal yellow bottles (509 flies); there is no significant difference between the two devices (Delpoux and Deguine 2015). Locally manufactured devices can be used, as well as the imported "yellow umbrella."

Tests with Synéis-appât ${ }^{\circledR}$ were effective against vegetable fly species present in Réunion. This bait is suitable for an agroecological crop protection program. In addition, thanks to our tests, the product was approved for use on some tropical crops (lychee, mango, star fruit, passion fruit, avocado, papaya, guava, and soursop) (Deguine 2013). Future research is needed on its effect on D. ciliatus, alternatives to Synéisappât ${ }^{\mathbb{R}}$, unintended effects, and effect on other fly species.

\subsection{Sexual trapping of $B$. cucurbitae and $D$. demmerezi males}

Sexual trapping is used in many parts of the world to assess fly population trends (surveillance trapping) with the aim of reducing numbers through mass trapping (Vargas et al. 2000a). Until 2010, in Réunion, traps were used containing both a parapheromone to attract adult males (Cue-lure) and an 
Fig. 10 Fruit fly trap without insecticide, constituted by a plastic bottle with four holes containing sexual parapheromone (Cue-lure) (photos: C Ajaguin Soleyen). a Trap placed in the field with dead flies inside. b Two males of $B$. cucurbitae entering the trap by the hole

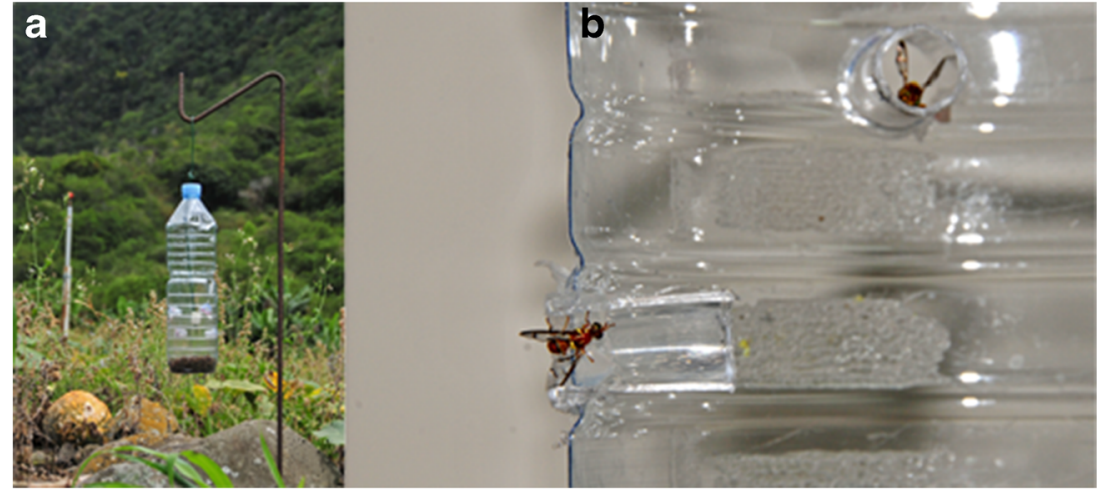

insecticide (diclorvos) killing adults upon entry into the trap. Cue-lure attracts $B$. cucurbitae and D. demmerezi males, but not the third species, $D$. ciliatus. The commercial traps are distributed on the island by the company Takamaka. However, new laws forbid the sale of these traps because of the diclorvos they contain. This is why tests were conducted to develop a new insecticide trapping system to monitor and control vegetable fly populations.

The commercial trap distributed by Takamaka is only useful if it is used with diclorvos; without it, flies escape too easily. An alternative system is based on a model used in Hawaii (Vargas et al. 2008) and consists of a plastic bottle in which four holes are pierced in the base, the holes extending into the interior by small tubes. The bottle contains a parapheromone, but does not contain an insecticide because flies that enter through the holes in the side of the trap remain trapped inside (Fig. 10).

Further trials compared the efficacy of insecticide-free traps developed before the insecticide trap and previously used by farmers. The trials took place in different places whereby two species of vegetable flies and a nonvegetable fruit fly, B. zonata occur. The tests showed that the traps without insecticide were at least as effective as the Takamaka $^{\circledR}$ trap. They are therefore a useful tool for MAT. In a context where insecticides need approval for use in sexual mass trapping, these tests led to the use of such traps by farmers in some pilot areas, with good results. This is now a commonplace technique. Several lengths of tube in bottles without insecticide were compared: the most effective length is $1 \mathrm{~cm}$.

This new trap can be used in organic farming and in agroecological crop protection systems (Deguine et al. 2008). The trapped insects proved very representative of the adult in field populations (Deguine et al. 2013) and were particularly appreciated by the farmers: it is simple, easy to make, low cost, uses no insecticides, and provides a positive psychological effect for the farmers related to the fact that a layer of dead flies can be seen at the bottom of the transparent bottle.

\subsection{Other agroecological techniques}

The techniques described above were reinforced by inundative biological control and implementation of a permanent plant cover. $P$. fletcheri were released by FDGDON in 2010-2011 on four Cucurbitaceae plots (Marquier et al. 2013, 2014). After these releases, the rate of parasitism increased moderately, with a maximum of $16.7 \%$ for B. cucurbitae. This may be a useful technique between altitudes of 0 $800 \mathrm{~m}$ (area where B. cucurbitae are present). Methods such as these encourage farmers to reduce their use of pesticides.

The elimination of chemical insecticides in Cucurbitaceae plots aims to promote the role and impact of functional biodiversity (predators, parasitoids, pollinators), as a conservation biological control. In chayote trellises where insecticides (pyrethroids and organophosphates) have been removed and in which a permanent plant cover was implemented in addition to GAMOUR techniques, there has been a significant increase in beneficial arthropods (e.g., predatory spiders). In GAMOUR-controlled plots, there has also been a significant increase in certain protected, iconic species (Réunion is one of the world's biodiversity hotspots), which play a regulatory role in the ecosystem.

Direct sowing, mulch-based and conservation (DMC) cropping systems preserve soil and crops and protect soil resources against damage from wind and/or water erosion and degradation of soil fertility. The three pillars of DMCs are (i) the absence of tillage, except for sowing furrows or planting holes; (ii) biodiversity resulting from increased phytodiversity following the elimination of monocultures and crops with high return frequency, diversification of crop rotations, and the introduction of beneficial plants; and (iii) soil cover resulting from cash crop residues or crops dedicated to biomass production and biodiversity (Derpsch and Friedrich 2009; Lienhard et al. 2013). The DMC system is perfectly compatible with agroecology principles as these three pillars complement other techniques, thus helping to minimize the damage caused by vegetable flies while maximizing insect biodiversity on GAMOUR production sites. Increasing plant diversity in agricultural landscapes and even 


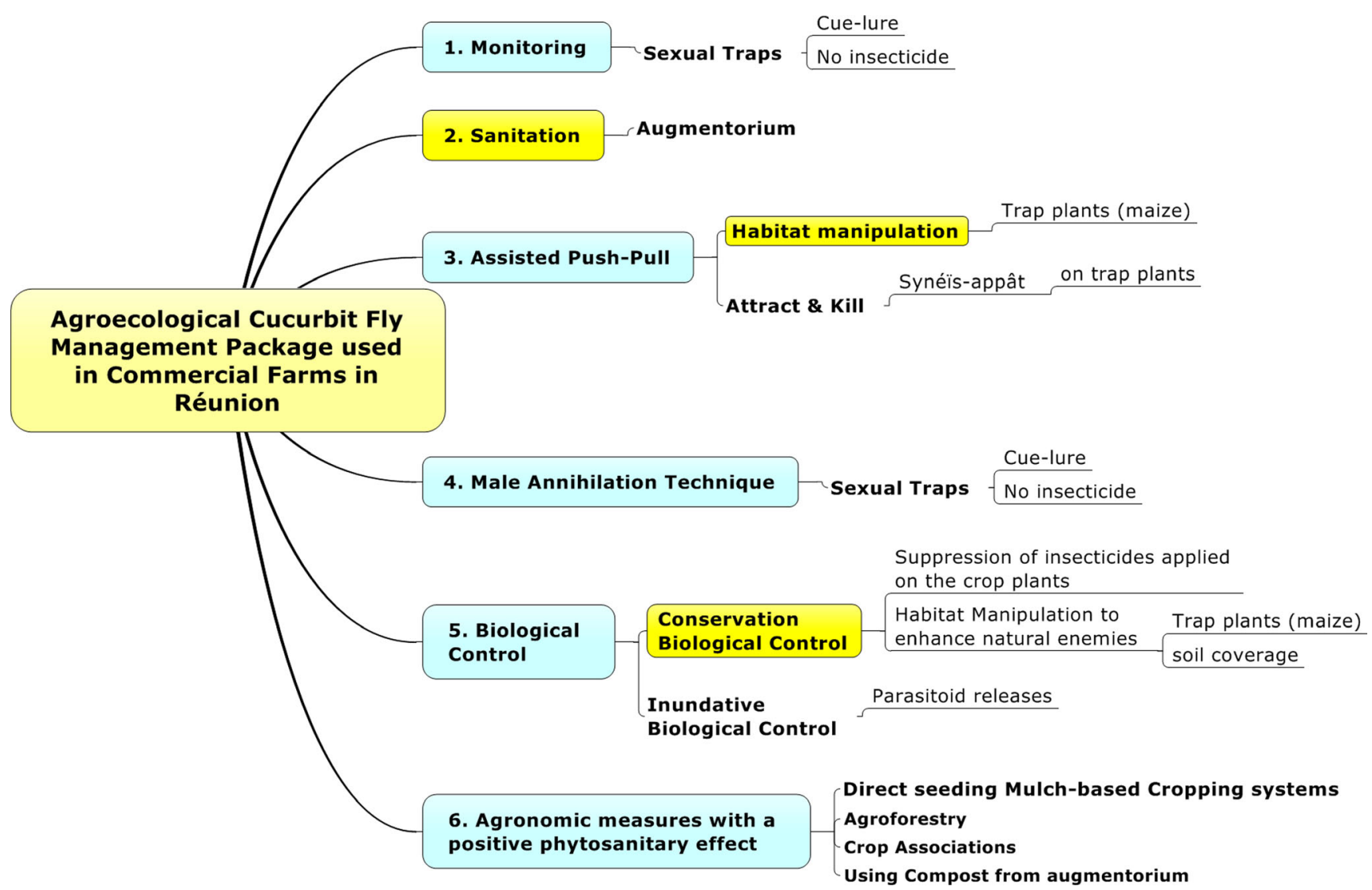

Fig. 11 Agroecological cucurbit fly management package used in commercial farms in Réunion

within crops is at the heart of ecological intensification (Papy and Goldringer 2011; Wezel et al. 2014). Several producers involved in the GAMOUR project have already completed the phytosanitary aspect of the program by setting up permanent plant coverage. In addition, certain agroecological techniques with both agronomic and phytosanitary benefits were adopted by some organic farmers: crop association, agroforestry, and composting in augmentoria.

Overall, in order to provide a sustainable solution to the problems posed by vegetable flies, different protection techniques have been combined in an innovative technology package (Fig. 11), based on the principles of agroecological crop protection.
Fig. 12 Evolution of adult males of Bactrocera cucurbitae and Dacus demmerezi in Salazie from September 2009 to November 2011

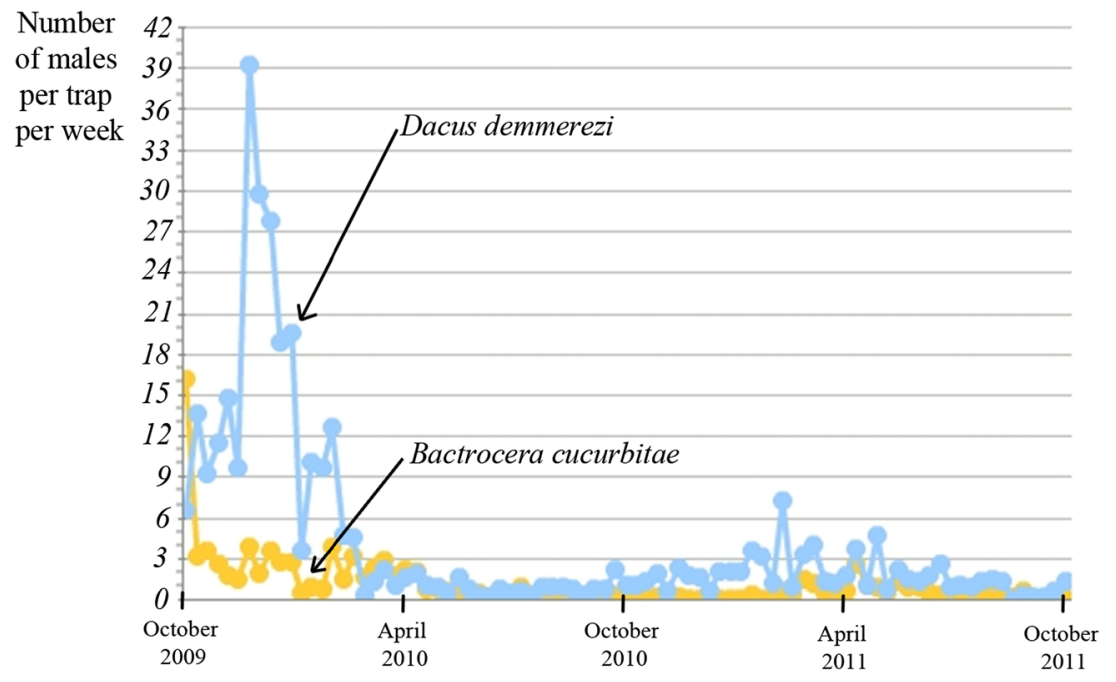


6 Technology, economical trends, and knowledge transfer

6.1 Socioeconomic performances and adoption of agroecological techniques by farmers

The GAMOUR project was set up in three villages (30 conventional farms over ca. $50 \mathrm{ha}$ ) and on four certified organic farms (Le Roux and Suzanne 2013; Fig. 2). An important goal of the project was to assess the socioeconomic performances of the agroecological techniques and to measure farmers' satisfaction. The diagnosis included (i) fly trapping in the pilot sites, (ii) crop monitoring, (iii) farm monitoring, and (iv) a perception survey of the farmers.

B. cucurbitae and D. demmerezi males were trapped from September 2009 (start of the GAMOUR project) to November 2011, in three villages (Entre-Deux, Petite Ile, and Salazie) using Cue-lure ${ }^{\circledR}$ (see technical Section 5.4; Fig. 12). For example, in Salazie, a drastic reduction in populations of flies was observed (11 traps placed in the Mare à Poules d'eau pilot site) since February 2010. A population peak during the 2010-2011 summer, although expected (see Section 4.2), did not occur. It can be hypothesized that the concerted, large-scale adoption of GAMOUR techniques in the pilot site contributed to the reduction in fly populations.

The assessment of economical performances of the GAMOUR techniques was achieved with the technical support of producers. All farmers were visited weekly during 2 years for material supply and to record yields, losses, and insecticide sprays. From 2009 to 2011, farmers were supplied with a grand total of 65 augmentoria, 636 traps baited with 2492 Cue-lure blocks, $69 \mathrm{~kg}$ of corn seeds, and 1361 of protein baits. In order to compare the performances of the GAMOUR techniques with conventional crop management, production data were observed in two similar production situations (such as defined by Aubertot and Robin (2013), i.e.,

Table 1 Consolidated data of the technico-economical survey of GAMOUR farms (Piton Bloc) and non-GAMOUR control farms (Piton Hyacinthe)

\begin{tabular}{|c|c|c|c|}
\hline \multicolumn{2}{|l|}{ Production data } & \multirow{2}{*}{$\begin{array}{l}\begin{array}{l}\text { Non-GAMOUR } \\
\text { zone (control) }\end{array} \\
\text { Piton Hyacinthe }\end{array}$} & \multirow{2}{*}{$\begin{array}{l}\begin{array}{l}\text { GAMOUR } \\
\text { zone }\end{array} \\
\text { Piton Bloc }\end{array}$} \\
\hline Pilot zone & & & \\
\hline Field surface $\left(\mathrm{m}^{2}\right)$ & Mean & 1980 & 1180 \\
\hline \multirow[t]{3}{*}{ Yield (t/ha) } & Mean & 13.1 & 19.3 \\
\hline & Min & 3.2 & 4.1 \\
\hline & $\operatorname{Max}$ & 20.9 & 31.4 \\
\hline \multirow[t]{3}{*}{ Losses $(\%)$} & Mean & 34 & 13 \\
\hline & Min & 5 & 0 \\
\hline & Max & 70 & 60 \\
\hline
\end{tabular}

Sources: Vivea, Terre Bourbon, farmers' declarations and field observations on 26 zucchini cultural cycles (2011); 19 GAMOUR crop cycles compared to 7 "control" cycles outside the GAMOUR area with similar altitudes, types of soils, climates, and natural vegetations). Nineteen zucchini crop cycles in the GAMOUR area (Piton Bloc) and seven in Piton Hyacinthe farms were monitored. Table 1 shows that zucchini yields were slightly higher in the GAMOUR farms and that losses due to fly infestations were lower in GAMOUR plots than in control plots. However, these data must be analyzed cautiously: They indeed were also influenced by other agronomic drivers (other phytosanitary problems and crop management plans) which could not always be accurately assessed. Without any reliable statistics, yield and losses are here considered similar in the control and GAMOUR farms. These data were mostly based on farmers' declarations, even though yields were confirmed as soon as possible by cooperative's certificates. The damages caused by flies were also assessed in the field by a counting of infested fruits on a randomly chosen 20-m cultural line (Augusseau et al. 2011).

In addition, sociotechnical and economical performances were assessed for conventional protection and agroecological protection, taking into account data from farmers' declarations in the GAMOUR zone (time devoted to crop protection) and from commercial information on the products in Réunion (characteristics and cost of the protection; Table 2). The more striking difference is the mean number of insecticide sprays, which have nearly disappeared in the GAMOUR farms. Globally, we can conclude that stopping the chemical cover sprays on crops and replacing them by agroecological practices had, at worst, no negative impact on production. This answers to the main concern initially expressed by the pilot farmers. On one hand, the global assessment of the costs of crop protection, combining material and manpower costs, revealed that the GAMOUR techniques were more than three times cheaper than conventional protection. On the other hand, the farmers' perceptions were somewhat more optimistic. They estimated GAMOUR's protection to be at least four times cheaper. Other areas of satisfaction (increased productivity, improved sanitary conditions, respect of auxiliary fauna) were noted and studied simultaneously. The final results of this pioneering project are very encouraging. Chemical insecticides have been discontinued on crops. Yield is at least as high as with chemical control and farmers are making significant financial savings.

The multiannual comparative yield production of chayote (perennial crop) was plotted in the main pilot site of Salazie for the pre-GAMOUR (mid 2007-mid 2009) and GAMOUR application periods (mid 2009-mid 2011). In this zone, production analysis involved weekly monitoring of 7.6 ha of chayote trellises. Figure 13 shows that chayote production was maintained at high level after the beginning of GAMOUR deployment, comparable or even higher than during the previous years.

The success of the GAMOUR techniques in the field has confirmed results obtained in controlled conditions and were quickly adopted by farmers. In particular, the use of maize 
Table 2 Technical and economical comparison between classical protection and agroecological protection

\begin{tabular}{|c|c|c|c|}
\hline Protection & Criteria & Classical protection & Agroecological protection \\
\hline \multirow[t]{5}{*}{ Characteristics } & Number of insecticide applications & 1.5 & 1 \\
\hline & Commercial products & Cyperfor-Danadim & Synéis-appât ${ }^{\circledR}$ \\
\hline & Active ingredients & Cypermethrine-dimethoate & Spinosad \\
\hline & Quantity of active ingredients applied (g/ha per application) & $45+450$ & 0.008 \\
\hline & Localization of the application & The entire field & Spots on trap plants \\
\hline \multirow[t]{5}{*}{ Time devoted } & Picking up infested fruit (h/ha/week) & 0 & $\begin{array}{l}2 \text { at the beginning and } 0.25 \text { after } \\
\text { a few weeks }\end{array}$ \\
\hline & Spraying (h/ha/week) & 4.5 & 1 \\
\hline & Setting sexual traps (h/ha/3 months) & 0 & 1 \\
\hline & Planting maize (h/cycle) & 0 & 10 \\
\hline & Total time of protection (week) & 4.5 & 4.1 \\
\hline \multirow[t]{2}{*}{ Cost } & Per week $(€)$ & 66 & 18 \\
\hline & Per cycle $(€)$ & 1320 & 370 \\
\hline
\end{tabular}

Sources: farmers' declarations in GAMOUR zone (time devoted to crop protection), commercial price of the products in Réunion (characteristics and cost of the protection)

borders (as a trap crop) around the fields can attract more than $95 \%$ of flies. These can then be efficiently eliminated with adulticide bait. Sexual trapping mass (without insecticide) is effective for two out of three Tephritidae. Similarly, sanitation is regularly practiced using an augmentorium (Deguine et al. 2011). These two latter techniques are particularly appreciated by farmers because they can directly observe the dead flies inside the traps or augmentoria.

Farmers were interviewed on all three GAMOUR pilot sites (Busnel and Augusseau 2011). The results showed (i) an overall satisfaction on both the effectiveness of the strategy and ease of implementation and (ii) difficulties moving from a curative strategy to a preventative control strategy.

For both chayote and zucchini, the results show a trend of increasing yields and reducing losses (Rousse et al. 2013). Despite their lack of accuracy, all these data are another milestone for cucurbit crop protection and, further, for the evolution of agricultural practices. Agreeing with other costbenefit analyses of similar programs in Hawaii, McGregor et al. (2007) showed that environmentally friendly agricultural practices might be profitable. This is a major step for extension of such agroecological practices, since economical viability is fundamental for sustainable development programs: Few farmers will agree to preserve their environment if they cannot "make both ends meet."

\subsection{Training and the participatory research and development}

GAMOUR has made available several study plots, which continue to be used in epidemiological surveillance by agricultural partners. These plots also serve as demonstration sites and for farmer training.

Training in agroecological practices was provided by FDGDON for farmers in pilot sites and technicians employed
Fig. 13 Multiannual yield comparison of chayote in the Salazie pilot area (Mare à Poules d'eau). Blue: before GAMOUR application (2007-2009); yellow: during GAMOUR application (2009-2011) (source: Vivéa Réunion)

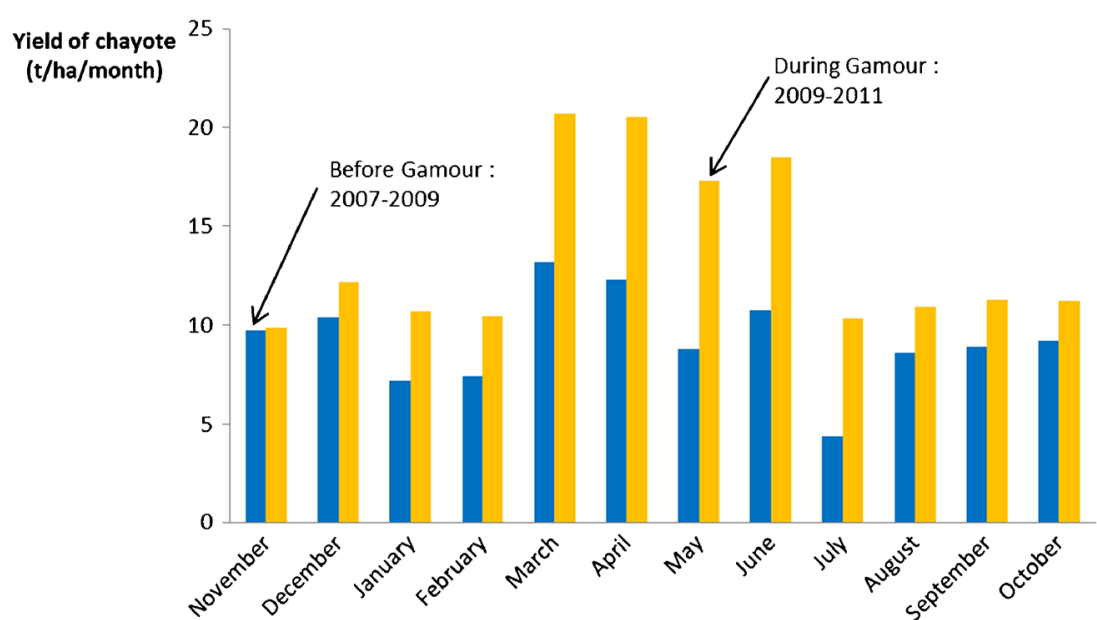


by organizations involved in the project. Datasheets were compiled on the biology of flies and agroecological techniques. The results were also recorded in a logbook which was distributed to farmers and technicians (Deguine et al. 2011). The technical recommendations are available on DVD and online at http://www.agriculture-biodiversite-oi. org/Professionnel-producteur/Se-former/Formations-enligne/Formation-video-a-la-gestion-agroecologique-desmouches-des-legumes.

The Réunion Chamber of Agriculture, Association of Fruit and Vegetable Producers (AROP-FL), FARRE Réunion, GAB (organic farmers), and other advisory bodies are now responsible for the popularization of the technical package to farmers around the island. However, the GAMOUR innovations must be accompanied by a major investment in training and leadership to guide the candidate farms. It is all the more necessary as there is a great diversity between vegetable farms and patchy access to existing agricultural support.

In general, farmers involved in GAMOUR improved their skills and acquired new knowledge and are able to fully implement a program of crop protection. This process is now known to be effective to implement new practices, particularly in organic farming (Lefèvre et al. 2014). This is one of the project's major success stories. A participatory process of knowledge transfer between farmers proved effective and is being continued. Farmers involved in the project are now able to implement the recommendations themselves. These producers have even become leaders in their production areas. Today, they are often asked by neighboring farms for advice on GAMOUR techniques. The AROP-FL (in Réunion) is involved in knowledge transfer to farmers via various professional organizations, and diffusion is adapted to needs and constraints.

\subsection{Transfer and dissemination of GAMOUR techniques}

GAMOUR brought together research and training organizations and agricultural consultancies under the aegis of supervisory bodies. This measure proved successful as result of effective coordination. This partnership is likely to continue in the future, given these results.

Since the end of the GAMOUR project, agricultural development organizations in Réunion have expressed the desire to popularize these techniques to all vegetable growers. Two years after the end of the project, the results are excellent (Vincenot 2014, personal communication; Réunion Chamber of Agriculture data): In 2012 and 2013, 683 farmers were trained in GAMOUR techniques. Of these, 130 farms (90 in 2012 and 40 in 2013) were closely monitored to assess the impact of GAMOUR techniques on cucurbit crops. The monitoring took place over a total area of 128 ha (84 ha in 2012 and 44 ha in 2013).
Sanitation was particularly successful (92\% of farmers used this technique and many of them used an augmentorium, particularly in 2012).

In support of new agroecological techniques, several innovative products have appeared on the local market:

- The augmentorium: This sanitation tool is now available from a company in Réunion, Takamaka Industries, which offers three sizes of augmentoria.

- Pheromone traps without insecticides developed under the project GAMOUR: These traps are now manufactured by Takamaka and sold to organizations, farmers, and individuals.

- Synéis-appât ${ }^{\mathbb{R}}$ : The tests in the GAMOUR project contributed to the approval of this product for use on tropical vegetable crops (tomato, eggplant, pepper, cucumber, zucchini, melon) and fruits (litchi, mango, star fruit, passion fruit, avocado, papaya, guava, soursop). Their use is a direct result of the trials undertaken during the GAMOUR project.

Training organizations have focused on several key points: availability of augmentoria, field training, provision of technical guides. The agroecological techniques used in Réunion are expected to be a part of adoption of other horticultural crops such as tomatoes, citrus, and mango as well as implemented in other areas of the southwest Indian Ocean, notably via the Regional Project Plant (e-PRPV).

6.4 GAMOUR: a catalyst in the development of organic farming

The techniques developed for agroecological management of vegetable flies are ideal for organic farming: sanitation with an augmentorium, inserting trap plants, use of Synéis-appât ${ }^{\circledR}$ (organic adulticide bait), and sexual trapping without insecticide. This package is also used in the management of fruit flies on citrus and mango.

In organic farming, changing in the choice of insecticide more environmentally friendly (low concentration and low toxicity to nontarget organism) encourages the return of beneficial arthropods and promotes conservation biological control (Hole et al. 2005; Simon et al. 2014). Generalist predators are therefore able to regulate pest populations (Symondson et al. 2002). In organic farming, probiodiversity agroecological practices are also available: permanent soil cover with agronomic properties including a reduction of soil erosion, improving soil fertility, limiting evapotranspiration and weed management, which provide favorable habitats for groundbased terrestrial predators (spiders, ants, Dermaptera) (Duyck et al. 2011) and flower strips for the development of Hymenoptera parasitoids, generalist predators, and pollinators. The observation that large populations of beneficial 
arthropods have been observed in organic farming and on farms where insecticides have been highly induced (GAMOUR farms) confirms the value of conservation biological control (Deguine and Penvern 2014).

Chayote, which was previously sprayed with large amounts of insecticides, has seen increased yields and some producers have been certified organic. Two years after GAMOUR, more than half the chayote farms in Salazie (the main chayote production area) are either certified organic or are in the process of being certified organic. GAMOUR techniques applied to chayote crops are not accompanied by a loss of yield; on the contrary, an increase in yield has been observed which farmers have attributed to the increased number of beneficial arthropods in chayote trellises following suppression of insecticide spraying. In addition to arthropods, other animals such as chameleons are on the rise. The GAMOUR project and the results obtained triggered the development of organic farming in Réunion particularly for chayote, one of the island's iconic crops. Finally, organic farms are ideal areas to study the functioning of communities and food webs in cropping systems because they are free from insecticide (Deguine and Penvern 2014). Organic chayote fruits are now sold in some supermarkets in Réunion.

\subsection{Scientific and technical breakthroughs and training}

Much knowledge was obtained during the project on the biology and ecology of the vegetable flies and on agroecological management techniques. This knowledge has been published in international scientific peer-reviewed journals with scientific books, papers, and posters presented at international conferences and various articles published in nonpeer-reviewed journals. In addition, the project has provided study possibilities for students: 11 masters, 4 engineer programs, and 2 volunteer positions. In addition, two students have achieved Ph.D programs based on the results obtained in the GAMOUR project: one on the genetic structure of populations of vegetable flies and the other on the attractiveness of olfactory stimuli of different species of Cucurbitaceae on flies.

During the project, lessons were given to many students, using GAMOUR as an example of the application of agroecological concepts in crop protection. Courses were offered at the University of Réunion (Faculty of Saint-Denis): Master 1 and Master 2 BEST (biology and ecology of terrestrial ecosystems); University of Réunion (Faculty of Le Tampon) Master 2 GUE (urban and environmental science); University of Réunion (IUT Saint-Pierre), 2nd year degree option in environmental engineering; video lessons: Bordeaux Agro Sciences, 3rd year; agricultural colleges, etc.

In addition, a distance learning module has been funded through the UVED (Virtual University in Environment and Sustainable Development). The module is entitled "invasive insects on islands and their agroecological management: the case of vegetable flies in Réunion" and the GAMOUR project is an important part of the module and is a collaboration between the National Museum of Natural History, the CIRAD, and the University of Réunion. The 20-h course consists of three submodules: (1) biological invasion and island ecosystems, focusing on insects in Réunion; (2) "biocontrol" against insect pests, an alternative to pesticides; and (3) an introduction to agroecology, followed by a presentation of the GAMOUR project. The module makes use of various media (Ipad/Iphone/epub/pdf/web): provides definitions, experimental and historical presentations of key concepts, interviews, and articles and data to analyze. Societal perception of biological invasions, biocontrol, and control methods used in GAMOUR are also discussed. The objectives of the module are to provide knowledge on various topics which the student can link to have a broader vision of the science. Scientific analyzing and interpreting skills will also be taught. Interactive questions allow self-assessment and students are directed to chapters or external links. Hosted on platformdepf.mnhn.fr, the distance learning server at the Natural History Museum, these resources are accessible free of charge after initial registration. The platform can be adapted to the specific needs of different Masters degrees and is reusable. This module will be initially offered to MNHN Masters Students (Ecology, Biodiversity, Environment, Development, Territories, and Communities) and at the University of Réunion (Tropical Biodiversity and ecosystems Master Degree, Urban and Environmental Engineering Master Degree). This module was first offered in 2014 and will be updated each year.

Finally, the various scientific and technical results were also presented in detail at an international seminar, held 2124 November 2011 in Saint-Pierre. The proceedings of the seminar, which was attended by over 80 participants, are compiled in a book available in French and English (Deguine 2013).

The GAMOUR project has a website aimed at the general public (gamour.cirad.fr). Many lectures have been given at public events such as the Festival of Science, in a film entitled "Nos enfants nous accuseront" at Le Tampon Library for the release of a book entitled "Crop Protection: from agrochemicals to agroecology," during the Sustainable Development Week, Bras Panon Show, Ecomarathon, at organic farming markets and more. In addition, several television and radio reports and news articles have appeared on GAMOUR, not only in the regional press but also in the national press. School awareness programs and public events have also been organized for young audiences, including a demonstration of the augmentorium, observations of arthropods under a magnifying glass, and school visits to CIRAD laboratories. The training and education continued throughout 2012, 2013 and 2014. 
6.6 An original example of vocational training in agroecological crop protection

Vocational training and agroecological practices gave rise to the GAMOUR project. A Professional University Qualification Certificate (CUQP) was designed to allow agricultural professionals, producers, and technicians to be trained in agroecological practices. The course is entitled "agroecological crop protection." The concept of agroecology must be understood and practices must be repeated by the trainees at the end of the course. This diploma took place over a period of $40 \mathrm{~h}$ spread over 2 weeks in 2013 and 2014 under the auspices of the IUT in Saint-Pierre, during the academic years $2012 / 2013$ and $2013 / 2014$. The innovative aspect of this course in crop protection is that it is supervised by different GAMOUR partners each bringing complementary skills: CIRAD, ARMEFLHOR, Chamber of Agriculture, FARRE, and FDGDON.

To date, 26 professionals (13 in 2013 and 13 in 2014) have graduated. This course is expected to continue to be offered and extended, in partnership with universities in neighboring countries of the Indian Ocean. A catalogue is now available (Deguine et al. 2014).

\section{Modeling perspectives}

GAMOUR efforts facilitated the development of further insights into the bioecology of vegetable flies and the effects of diverse control methods in production situations in Réunion (see Sections 3 and 4). Complex dynamic interactions occur between life cycle of these flies and (i) soil and weather variables, (ii) crops and other anthropized spatial units, (iii) natural habitats, (iv) natural enemies, (v) cropping practices (including the control methods used in the GAMOUR project), and (vi) the landscape structure. In order to cope with this high level of complexity, modeling appears to be a key tool to employ in the design of agroecological crop protection strategies as it is used to predict cultivar performances (Jeuffroy et al. 2014). Modeling approaches could be developed at three levels: the field level, the regional level, and the island level.

\subsection{Modeling at the field level}

The field level is relevant for the optimization of individual crop management practices since farmers generally decide their technical operations at the field level. However, due to the dispersal ability of flies, this level is not relevant with regard to the bioecology of the three flies under study: B. cucurbitae, D. ciliatus, and D. demmerezi. In order to solve this apparent conflict, one might use a nonspatially explicit modeling approach that uses simple descriptors of the field environment as input variables. The Injury Profile SIMulator

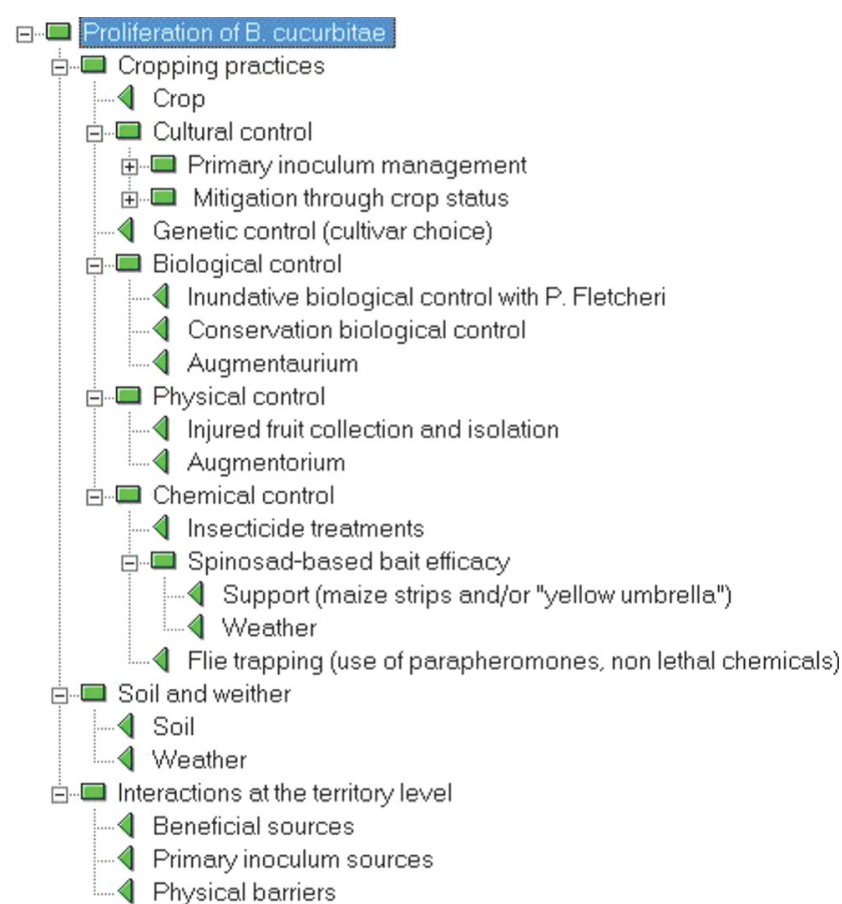

Fig. 14 Adaptation of the qualitative IPSIM modeling framework (Aubertot and Robin 2013) for the agroecological control of B. cucurbitae at the field level. This hierarchical modeling structure was designed using DEXi (Bohanec 2009)

(IPSIM; Aubertot and Robin 2013) hierarchical qualitative modeling approach could certainly be used successfully to help design agroecological strategies in various production situations in Réunion. One of the main features of this approach is its simplicity despite the high level of complexity that it can handle. This innovative modeling approach has been successfully applied to eyespot on wheat (Robin et al. 2013). Figure 14 illustrates the adaptation of the generic IPSI $\mathrm{M}$ framework to noxious flies on vegetable. This structure could be further developed and aggregative tables could be defined using available knowledge in the international literature and specific knowledge produced by the GAMOUR project.

Another approach that could be easily implemented to help design agroecological solutions to manage flies on vegetables in Réunion is the DEXiPM modeling approach (Pelzer et al. 2012). The basic principle of this approach is to characterize, ex-post or ex-ante, the environmental, social, and economic performances of cropping systems using qualitative or quantitative input variables describing cropping practices and the environment. The main interest of this approach would be to broaden the evaluation of agroecological solutions to manage pests, such as promoted by the GAMOUR project.

In addition to the design of integrated agroecological solutions to manage vegetable flies in the island with simulations, such tools (IPSIM and DEXiPM) could ease and strengthen communication among the actors involved: agroecologists, 
entomologists, agronomists, crop protection specialists, landscape managers, advisors, farmers, and students.

\subsection{Modeling at the regional level}

Another modeling approach could be developed at the regional level in order to (i) better understand the fly population dynamics in agroecosystems and (ii) help design collective agroecological strategies to manage these flies. The region under study would typically extend over a few square kilometers. A first approach could consist in developing an individually based model such as the one developed by Vinatier et al. $(2012 a, b)$. The main interest of this approach would be to integrate the knowledge produced by GAMOUR and the knowledge available in the literature in a unique tool that would represent interactions among fly populations, their parasitoids, the landscape composition, and spatial distribution, along with the effects of cropping practices. Along the line of the SIPPOM-WOSR model (Lô-Pelzer et al. 2009) in the case of phoma stem canker on oilseed rape, this model could be used to help design collective strategies that combine adapted cropping practices and landscape management for the sustainable management of flies on vegetables. Lastly, networks, such as Graph-based Markov Decision Process networks (Tixier et al. 2013), could also be used to describe trophic chains and/or spatial interactions at the regional scale, provided that the spatial elements are not too numerous.

\subsection{Modeling at the island level}

Unlike classical modeling approaches for continental territories, islands include natural coastal boundaries that strongly limit pest migration from other territories. In these situations, pest introduction essentially results from human activity (freight and transportation). Two types of modeling approaches could therefore be considered. First, one could aim at optimizing sampling strategies to prevent the introduction of invasive species. Approaches such as chain risk modeling (Benninga et al. 2012) could be used to design a collective monitoring strategy to limit the introduction of invasive pests such as flies. The second approach would consist in breaking down the island into contrasting production situations as a function of weather regimes, soil, altitude, natural habitats, and value chains. Using that typology and the spatial distribution of these production situations, it would therefore be possible, using modeling tools such as IPSIM, to design cropping systems that limit the development of flies.

\subsection{Partial conclusion}

The bioecological knowledge and the associated agroecological strategies developed by the GAMOUR project could be extended by the modeling approaches mentioned above. The main benefit of these modeling extensions would be (i) to ease interactions between the agroecological actors involved, (ii) to ensure the robustness of the proposed solutions, and (iii) to generalize the approach for production situations outside of Réunion. Beyond simulations, modeling activities can help structure research and development programs that pull together various actors: researchers, advisors, farmers, cooperative representatives, food chain operators, and public authorities. From a scientific point of view, conceptual modeling helps organize interactions between methodological approaches: experiments (in field, greenhouse, or laboratory), diagnoses in commercial fields and their surroundings, and simulation modeling. Since agroecological crop protection requires knowledge from various scientific disciplines, modeling can also be seen as a powerful tool to formalize their integration in a unique framework and to ease its implementation in the agricultural sphere.

\section{Conclusion}

Research \& Development activities conducted in Réunion have given us more effective, cheaper, environmentally friendly, healthy, and sustainable agroecological crop protection. It is fully compatible with the national plan of pesticide reduction in agriculture (http://agriculture.gouv.fr/ecophyto). GAMOUR has met its initial objectives. As a reward for good performance, the project received a Special Mention in the sustainable agriculture 2011 awards (organized by the French Ministry of Agriculture, Food, Fisheries, Rural Affairs and Planning). This award has helped publicize the project around the country.

The discontinuation of insecticides, such as pyrethroids and organophosphates, on crops has given a healthy new image to agriculture. As produce is free from chemical insecticide, commercial exploitation is currently under study. Cucurbit production using GAMOUR methods showed that it was possible to greatly reduce, or even eliminate, the use of insecticides on crops. Monetary savings were significant, making farming more profitable. In an island which is a hotspot of biodiversity, a UNESCO World Heritage Site with $40 \%$ of the territory now a National Park, the new attitude of environmental respect promoted by the GAMOUR project has given farms a clean new image. Another positive point is bees: Farmers and beekeepers recognize and appreciate that GAMOUR methods preserve and attract wildlife and pollinators.

Through GAMOUR, a great deal of academic knowledge has been acquired; agroecological techniques have been developed and evaluated; farmers now use cheaper, more efficient, and more environmentally friendly practices; an organic-approved technical package is available; and agricultural partners are now ready to continue their partnerships and 
collaborate on other integrative projects. Now that agroecological protection techniques have proven effective and transferable, post-project studies will look at the implementation of agroecological protection to all vegetable growers on the island. Agroecological techniques will also be applied to other horticultural crops such as tomato and mango.

GAMOUR has developed a matrix of socioeconomic and environmental indicators for the control of subsequent experiments. It has also identified several conditions necessary (but not sufficient) for a successful research and development project: a good project design, distributing work to relevant partnerships, establishing good coordination and a rigorous follow-up, and keeping a strict schedule. In future projects, the economic and commercial advantages of agroecological production will be taken into account.

Based on GAMOUR experience, another project called Biophyto was implemented in 2012 (www.agriculturebiodiversite-oi.org/Nature-agriculture /Actualites/ Dossierspro/Biophyto), financed by CASDAR (2012-2014), assessing the feasibility of producing mangoes without insecticides through the implementation of agroecological crop protection practices. This project involves 12 partners in research, testing, training, and development. The objective is to develop and evaluate agroecological crop protection in conventional and organic farms based on plant community management (vegetal ground cover, vegetal strips, and trap plants).

The results are encouraging, particularly plant biodiversity in orchards (permanent ground cover, flower strips), functional biodiversity (characterization, evolution, impact of agroecological practices), and impact on trade. Other areas have also been the subject of technology transfer including development, training, and education. This project strengthens the agroecological crop protection already underway in Réunion.

Acknowledgments The authors would like to thank all Cucurbit producers who agreed to take part in the GAMOUR trials. Their participation, particularly in educating the general public on the effectiveness of these techniques, was much appreciated and contributed greatly to the success of the project. We also thank our partners who were involved in the project: C. Ajaguin Soleyen, E. Douraguia, M.-L. Moutoussamy, S. Quilici (CIRAD), Insa G., B. Logoras, E. Trulès (ARMEFLHOR), E. Poulbassia, Gros ${ }^{2}$ who expertly supervised the GAMOUR project, Y. Soupapoullé, P. Tilma (Chamber of Agriculture), K. Le Roux, W. Suzanne (FARRE Réunion), C. Clain, V. Duffourc, C. Festin, Mr. Marquier, E. Roux (FDGDON), Mr. Jolet (Association of Organic Farms), D. Morel, T. Taye (Takamaka Industries), and A. Cornu (Emerald). We also wish to thank those who have contributed in drafting or reviewing this manuscript, especially N. Becker and L. Deguine. We are grateful to our Hawaiian colleagues at USDA and the University of Hawaii, R. Vargas, E. Jang, R. Mau, G. McQuate, and M. Klungness. Finally, we extend our gratitude to the Ministry of Agriculture, Food, Fisheries, Rural Affairs and Spatial Planning, which funded the GAMOUR project via the Trust Account for Agricultural and Rural Development (CASDAR). The Regional Council of Réunion, the General Council of Réunion, the French Government, the European Union (ERDF, EAFRD), and the CIRAD also funded research and trialing. We thank our other partners for their contribution to this project: The Water Agency, Dow AgroSciences and the Crédit Agricole of Réunion (technical supplies organization of the final seminar), and e-PRPV Project for financing of acts of the final GAMOUR seminar.

\section{References}

Altieri MA (1987) Agroecology: the scientific basis of alternative agriculture. Westview Press, Boulder

Altieri MA (1994) Biodiversity and pest management in agroecosystems. Food Product Press, New York

Altieri MA (1999) The ecological role of biodiversity in agroecosystems. Agric Ecosyst Environ 74:19-31. doi:10.1016/S0167-8809(99) 00028-6

Altieri MA, Nicholls CI (1999) Biodiversity, ecosystem function, and insect pest management in agricultural systems. In: Collins WW, Qualset CO (eds) Biodiversity in agroecosystems. CRC Press, Boca Raton, pp 69-84

Altieri MA, Nicholls CI (2004) Biodiversity and pest management in agroecosystems. Food Products Press, Binghamton

Altieri MA, Nicholls CI (2005) Agroecology and the search for a truly sustainable agriculture. Unep, Mexico

Altieri MA, Nicholls CI (2012) Agroecological diversification strategies to enhance biological pest regulation in horticultural systems. Acta Hort 933:35-41

Altieri MA, Rosset P (1996) Agroecology and the conversion of largescale conventional systems to sustainable management. Intern J Environ Stud 50:165-185

Altieri MA, Funes-Monzote FR, Petersen P (2012) Agroecologically efficient agricultural systems for smallholder farmers: contribution to food sovereignty. Agron Sustain Dev 32:1-13. doi:10.1007/s13593011-0065-6

Andow D (1983) The extent of monoculture and its effects on insect pest populations with particular reference to wheat and cotton. Agric Ecosyst Environ 9:25-35. doi:10.1016/0167-8809(83)90003-8

Andow D (1991) Vegetational diversity and arthropod population response. Annu Rev Entomol 36:561-585. doi:10.1146/annurev.en. 36.010191.003021

Atiama-Nurbel T, Deguine JP, Quilici S (2012) Maize more attractive than Napier grass as non-host plants for Bactrocera cucurbitae and Dacus demmerezi. Arthropod-Plant Interact: 395-403. doi:10.1007/ s11829-012-9185-4

Atiama-Nurbel T, Ajaguin Soleyen C, Atiama M, Bonnet E, Douraguia E, François T, Gilles B, Moutoussamy ML, Chiroleu F, Petite A, Quilici S, Tenailleau M, Deguine JP (2013) Rythme circadien et activité et des mouches des Cucurbitaceae à La Réunion. Actes du séminaire de clôture du projet Gamour, Saint-Pierre (Réunion), pp 105-107

Atkinson D, McKinlay RG (1997) Crop protection and its integration within sustainable farming systems. Agri Ecosys Environ 64:8793. doi:10.1016/S0167-8809(97)00026-1

Aubertot JN, Robin MH (2013) Injury Profile SIMulator, a qualitative aggregative modelling framework to predict injury profile as a function of cropping practices, and abiotic and biotic environment. I. Conceptual bases. PLoS ONE 8:e75829. doi:10.1371/journal. pone.0075829

Audemard H (2003) Protection raisonnée et protection intégrée des cultures : concepts et bases. ADALIA-Bull. inf. tech. Club Protect Raisonnée 50:22-25

Augusseau X, Deguine JP, Douraguia E, Duffourc V, Gourlay J, Insa G, Lasne A, Le Roux K, Poulbassia E, Rousse P, Roux E, Suzanne W, Tilma P, Trules E (2011) Gamour, l'agroécologie en action à Reunion. Phytoma 642:33-37 
Aviron S, Burel F, Baudry J, Schermann N (2005) Carabid assemblages in agricultural landscapes: impacts of habitat features, landscape context at different spatial scales and farming intensity. Agric Ecosyst Environ 108(3):205-217. doi:10.1016/j.agee.2005.02.004

Barbosa P (1999) Conservation biological control. Academic Press, San Diego

Batáry P, Holzschuh A, Orci KM, Samu F, Tscharntke T (2012) Responses of plant, insect and spider biodiversity to local and landscape scale management intensity in cereal crops and grasslands. Agric Ecosyst Environ 146:130-136. doi:10.1016/j.agee.2011.10. 018

Bateman MA (1972) The ecology of fruit flies. Annu Rev Entomol 17: 493-518. doi:10.1146/annurev.en.17.010172.002425

Benninga J, Hennen WHGJ, Schans J (2012) Supply chain risk model for quantifying the cost-effectiveness of phytosanitary measures. Crop Prot 32:64-70. doi:10.1016/j.cropro.2011.11.001

Bertile W (1987) Réunion - Atlas thématique et régional. Saint Denis, Réunion

Bianchi FJJA, Booij CJH, Tscharntke T (2006) Sustainable pest regulation in agricultural landscapes: a review on landscape composition, biodiversity and natural pest control. Proc R Soc 273:1715-1727. doi:10.1098/rspb.2006.3530

Bohanec M (2009) DEXi: program for multi-attribute decision making, version 3.02. Jozef Stefan Institute, Ljubljana. Available: http:// www-ai.ijs.si/MarkoBohanec/dexi.html. Accessed 22 Nov 2012

Brévault T, Quilici S (2007) Influence of habitat pattern on orientation during host fruit location in tomato fruit fly, Neoceratitis cyanescens. B Entomol Res 97:637-642. doi:10.1017/ S0007485307005330

Brévault T, Quilici S (2009) Oviposition preference in the oligophagous tomato fruit fly, Neoceratitis cyanescens. Entomol Exp Appl 133: 165-173. doi:10.1111/j.1570-7458.2009.00913.x

Burel F, Baudry J (1999) Ecologie du paysage. Concepts, méthodes et applications. TEC \& DOC, Paris

Burns RE, Harris DL, Moreno DS, Eger JE (2001) Efficacy of spinosad bait sprays to control Mediterranean and Caribbean fruit flies (Diptera: Tephritidae) in commercial citrus in Florida. Fla Entomol 84:672-678

Busnel J, Augusseau X (2011) Analyse de l'évaluation du projet GAMOUR et de l'appropriation des pratiques par les maraîchers des zones pilotes. Stage de césure. AgroParisTech, Paris

Cardinale BJ, Srivastava DS, Duffy JE, Wright JP, Downing AM, Sankaran M, Jouseau C (2006) Effects of biodiversity on the functioning of trophic groups and ecosystems. Nat Lett 443:989-992. doi: 10.1038 /nature 05202

Carey JR (1984) Host specific demographic studies of Mediterranean fruit fly Ceratitis capitata. Ecol Entomol 9:261-270. doi:10.1111/ j.1365-2311.1984.tb00850.x

Carroll CR, Vandermeer JH, Rosset PM (1990) Agroecology. McGraw Hill, New York

Carson R (1962) Silent spring. The Riverside Press, Cambridge

Christenson LD, Foote RH (1960) Biology of fruit flies. Annu Rev Entomol 5:171-192. doi:10.1146/annurev.en.05.010160.001131

Clarke AR, Powell KS, Weldon CW, Taylor PW (2011) The ecology of Bactrocera tryoni (Diptera: Tephritidae): what do we know to assist pest management? Ann Appl Biol 158:26-54. doi:10.1111/j.17447348.2010.00448.x

Clough Y, Kruess A, Tscharntke T (2005) Organic versus conventional arable farming systems: functional grouping helps understand staphylinid response. Agric Ecosyst Environ 118(1-4):285-290. doi:10. 1016/j.agee.2006.05.028

Cole LJ, McCracken DI, Dennis P, Downie IS, Griffin AL, Foster GN, Murphy KJ et al (2002) Relationships between agricultural management and ecological groups of ground beetles (Coleoptera: Carabidae) on Scottish farmland. Agric Ecosyst Environ 93(1-3): 323-336. doi:10.1016/S0167-8809(01)00333-4
Corey SA, Dall DJ, Milne WM (1993) Pest control and sustainable agriculture. CSIRO, Australia

Costa CA, Godinho MC, Duarte S, Mateus C, Figueiedo E, Mexia A (2012) Functional biodiversity and farming techniques: how to measure impacts? Proceedings of the XXIIIth IHC-IS on organic horticulture: productivity and sustainability. EdsMourão I, Aksoy U (eds). Acta Hort 933:455-462

Costanzo A, Bàrberi P (2014) Functional agrobiodiversity and agroecosystem services in sustainable wheat production. A review. Agron Sustain Dev 34(2):327-348. doi:10.1007/ s13593-013-0178-1

Dalgaard T, Hutchings NJ, Porter JR (2003) Agroecology, scaling and interdisciplinarity. Agric Ecosyst Environ 100:39-51. doi:10.1016/ S0167-8809(03)00152-X

De Meyer M (2000) Phylogeny of the genus Ceratitis (Dacinae: Ceratitidini). Crc Press-Taylor \& Francis Group, Boca Raton

Deguine JP (ed.) (2013) Gestion agroécologique des Mouches des légumes à La Réunion. Séminaire final du projet Gamour. 21-24 novembre 2011, Saint-Pierre

Deguine JP, Penvern S (2014) Agroecological crop protection in organic farming: relevance and limits. In: Bellon S, Penvern S (eds.), Organic farming, prototype for sustainable agricultures, pp 107 130. doi:10.1007/978-94-007-7927-3_6

Deguine JP, Ratnadass A (2013) Gestion des habitats. In: Thiery D, Calatayud PA, Sauvion N, Marion-Poll F (eds), Des insectes et des plantes. Publibook et Editions IRD, pp 719-730

Deguine JP, Ferron P, Russell D (2008) Sustainable pest management for cotton production. A review. Agron Sustain Dev 28:113-137. doi: 10.1007/978-90-481-2666-8 27

Deguine JP, Ferron P, Russell D (2009) Crop protection: from agrochemistry to agroecology. Science Publishers, Enfield, $190 \mathrm{p}$

Deguine JP, Atiama-Nurbel T, Rousse P (2011) L'augmentorium, un outil de protection agroécologique des cultures. Conception et évaluation en milieu producteur à l'île de La Réunion. Cah Agric 20:261-265

Deguine JP, Atiama M, Lavigne A (2012a) Dynamique des populations de Mouches des légumes durant l'hiver austral à La Réunion. Cah Agric 21:395-403

Deguine JP, Atiama-Nurbel T, Douraguia E, Chiroleu F, Quilici S (2012b) Species diversity within a community of the Cucurbit fruit flies Bactrocera cucurbitae, Dacus ciliatus and Dacus demmerezi roosting in corn borders near cucurbit production areas of Reunion Island. J Insect Sci 12:32. doi:10.1673/031.012.3201

Deguine JP, Douraguia E, Atiama-Nurbel T, Chiroleu F, Quilici S (2012c) Cage study of spinosad-based bait efficacy on Bactrocera cucurbitae, Dacus ciliatus and Dacus demmerezi in Reunion Island. J Econ Entomol 105:1358-1365. doi:10.1673/031.012.3201

Deguine JP, Atiama-Nurbel T, Delpoux C, Douraguia E, Gilles B, François T, Ajaguin-Soleyen C, Moutoussamy ML, Quilici S (2013) Gestion agroécologique des populations de Mouches des légumes en culture de chouchou (Sechium edule). Actes du séminaire de clôture du projet Gamour, Saint-Pierre (Réunion), $125-126$

Deguine JP, Ajaguin Soleyen C, Atiama M, Festin C, Folio N, Gloanec C, Graindorge R, Jacquot M, Le Roux K, Moutoussamy ML, Muru D, Roux E, Suzanne W, Vincenot D, Laurent P (2014) Application de l'agroécologie à la protection des cultures. Support de formation, Certificat Universitaire de qualification Professionnelle. Institut Universitaire de Technologie de La Réunion (Saint Pierre), 81 pp

Dehecq JS (1995) Etude du comportement sexuel et de la communication phéromonale chez trois tephritidae de Reunion : Dacus ciliatus Loew, Dacus demmerezi (Bezzi) et Trirhithromyia cyanescens (Bezzi). Ecole Nationale Supérieure Agronomique de Montpellier, Montpellier

Delpoux C, Deguine JP (2015) Implementing a spinosad-based local bait station to control Bactrocera cucurbitae (Diptera, Tephritidae) in 
high rainy areas of Reunion Island. J Insect Sci. doi:10.1093/jisesa/ ieu177

Derpsch R, Friedrich T (2009) Global overview of conservation agriculture adoption. Proceedings, Lead Papers, 4th World Congress on Conservation Agriculture, 4-7 February 2009, New Delhi, India, pp 429-438

Dhillon MK, Singh R, Naresh JS, Sharma HC (2005) The melon fruit fly, Bactrocera cucurbitae: a review of its biology and management. J Insect Sci 5:40

Drew RAI, Hooper GHS (1983) Population studies of fruit flies in Southeast Queensland. Oecologia 56:153-159. doi:10.1007/BF00379685

Duhautois S (2010) Structuration des communautés de Diptères sur le maïs, Zea mays, utilisé comme plante piège à La Réunion. Master 2 Biologie de l'évolution et écologie, Université Montpellier 2

Dupraz C (2005) Entre agronomie et écologie : vers la gestion d'écosystèmes cultivés. In: Demeter 2006. Éditions Club Demeter, Paris

Duyck PF, Lavigne A, Vinatier F, Achard F, Okolle JN, Tixier P (2011) Addition of a new resource in agroecosystems: do cover crops alter the trophic positions of generalist predators? Basic Appl Ecol 12: 47-55. doi:10.1016/j.baae.2010.11.009

Ehler LE (2006) Integrated pest management (IPM): definition, historical development and implementation, and the other IPM. Pest Manag Sci 62:787-789. doi:10.1002/ps.1247

Ehler LE, Bottrell DG (2000) The illusion of integrated pest management. Issues Sci Technol 16:61-64

Eilenberg J, Hajek A, Lomer C (2001) Suggestions for unifying the terminology in biological control. Bio Control 46:387-400. doi:10. 1023/A:1014193329979

Elliott NC, Kieckhefer RW, Lee JH, French BW (1998) Influence of within-field and landscape factors on aphid predator populations in wheat. Landsc Ecol 14:239-252. doi:10.1023/A:1008002528345

Etienne J (1972) Les principales Tephritides de l'ile de Réunion. Ann Soc Entomol Fr 8(2):485-491

Etienne J (1982) Etude systématique, faunistique et écologique des Tephritides de Réunion. Thèse de l'Ecole Pratique des Hautes Etudes, Paris

Fernandes-Da-Silva PG, Zucoloto FS (1993) The influence of host nutritive value on the performance and food selection in Ceratitis capitata (Diptera, Tephritidae). J Insect Physiol 39:883-887. doi: 10.1016/0022-1910(93)90121-7

Ferron P (1999) Protection intégrée des cultures : évolution du concept et de son application. Cah Agric 8:386-396

Ferron P, Deguine JP (2005) Crop protection, biological control, habitat management and integrated farming. A review. Agron Sustain Dev 25:17-24. doi:10.1007/978-90-481-2666-8 29

Fiedler AK, Landis DA, Wratten SD (2008) Maximizing ecosystem services from conservation biological control: the role of habitat management. Biol Control 45:254-271. doi:10.1016/j.biocontrol.2007. 12.009

Fitt GP (1986) The influence of a shortage of hosts on the specificity of oviposition behaviour in species of Dacus (Diptera, Tephritidae). Physiol Entomol 11:133-143. doi:10.1111/j.1365-3032.1986. tb00400.x

Fletcher BS (1987) The biology of Dacine fruit flies. Annu Rev Entomol 32:115-144. doi:10.1146/annurev.en.32.010187.000555

Fullaway DT (1920) The melon fly: its control in Hawaii by a parasite introduced from India. Hawaii Forester Agric 17:101-105

Gaba S, Fried G, Kazakou E, Chauvel B, Navas ML (2014) Agroecological weed control using a functional approach: a review of cropping systems diversity. Agron Sustain Dev 34(1):103-119. doi:10.1007/s13593-013-0166-5

Gliessman SR (2007) Agroecology: the ecology of sustainable food systems. CRC Press, Taylor \& Francis, NY
Gurr GM, Wratten SD, Lunac JM (2003) Multi-function agricultural biodiversity: pest management and other benefits. Basic Appl Ecol 4:107-116. doi:10.1078/1439-1791-00122

Gurr GM, Wratten SD, Altieri MA (2004) Ecological engineering for pest management. Advances in habitat manipulation for arthropods. CSIRO, Collingwood VIC Australia and CABI Publishing, Wallingford

Haeckel E (1866) Generelle Morphologie des Organismus, Bd. 2 : Allgemeine Entwicklungsgeschichte. Reprint 1998: de Gruyter

Hagen KS, Finney GL (1950) A food supplement for effectively increasing the fecondity of certain tephritid species. J Econ Entomol 43:735

Hardee DD, Henneberry TJ (2004) Area-wide management of insects infesting cotton. In: Horowitz AR, Ishaaya I (eds) Insect pest management. Field and protected crops. Springer-Verlag, Berlin, pp 140-199

Harper TL (1974) Agricultural ecosystems. Agro-Ecosystems 1:1-6

Hénin S (1967) Les Acquisitions techniques en production végétale et leur application. Écon Rural 74:37-44

Hole DG, Perkins AJ, Wilson JD, Alexander IH, Grice PV, Evans AD (2005) Does organic farming benefit biodiversity? Biol Conserv 122:113-130. doi:10.1016/j.biocon.2004.07.018

Holway DA, Lach L, Suarez AV, Tsutsui ND, Case TJ (2002) The causes and consequences of ant invasions. Annu Rev Ecol Syst 33:181233. doi:10.1146/annurev.ecolsys.33.010802.150444

Hooper DU, Chapin FS III, Ewel JJ, Hector A, Inchausti P, Lavorel S, Lawton JH, Lodge DM, Loreau M, Naeem S, Schmid B, Setälä H, Symstad AJ, Vandermeer J, Wardle DA (2005) Effects of biodiversity on ecosystem functioning: a consensus of current knowledge. Ecol Monogr 75:3-35

Horowitz AR, Ishaaya I (2004) Insect pest management. Field and protect crops. Springer Verlag, Berlin

Isbell F, Calcagno V, Hector A, Connolly J, Harpole WS, Reich PB, Scherer-Lorenzen M, Schmid B, Tilman D, Van Ruijven J, Weigelt A, Wilsey BJ, Zavaleta ES, Loreau M (2011) High plant diversity is needed to maintain ecosystem services. Nat Res Lett 477:199-202. doi:10.1038/nature10282

Îto Y, Koyama J (1982) Eradication of the melon fly: role of population ecology in the successful implementation of the sterile insect release method. Prot Ecol 4:1-28

Jang EB, Klungness LM, McQuate GT (2007) Extension of the use of augmentoria for sanitation in a cropping system susceptible to the alien Tephritid fruit flies (Diptera: Tephritidae) in Hawaii. J Appl Sci Environ Manag 11:239-248

Jarvis DI, Padoch C, Cooper HD (2006) Managing biodiversity in agricultural ecosystems. Columbia University Press, New York

Jeuffroy MH, Casadebaig P, Debaeke P, Loyce C, Meynard JM (2014) Agronomic model uses to predict cultivar performance in various environments and cropping systems. A review. Agron Sustain Dev 34(1):121-137. doi:10.1007/s13593-013-0170-9

Jones EL, Skepper AH (1965) Suppression of Queensland fruit fly, Dacus tryoni (Frogg.), Trypetidae (Dip) in Narrendera. Agric Gaz NSW 76: 501-503

Kehrli P, Lehmann M, Bacher S (2004) Mass-hatching devices: a new biocontrol technique to augment parasitoids. Biol Control 32:191199

Klungness LM, Jang EB, Ronald FL, Vargas RI, Sugano JS, Fujitani E (2005) New sanitation techniques for controlling tephritid fruit flies (Diptera: Tephritidae) in Hawaii. J Appl Sci Environ Manag 9:5-14. doi:10.4314/jasem.v9i2.17284

Knipling EF (1955) Possibilities of insect control or eradication through the use of sexually sterile males. J Econ Entomol 48:459-462

Köppler K, Kaffer T, Vogt H (2008) Bait sprays against the European cherry fruit fly Rhagoletis cerasi: status quo \& perspectives. In: Boos M (ed) Ecofruit - 13th International Conference on cultivation technique and phytopathological problems in organic fruit-growing. Boos, Weinsberg, pp 102-108 
Koul O, Cuperus GW (2007) Ecologically-based integrated pest management. Cabi Publishing, Wallingford

Koul O, Dhaliwal GS, Cuperus GW (2004) Integrated pest management - potential, constraints and challenges. Cabi Publishing, Wallingford

Koul O, Cuperus G, Elliot N (2008) Areawide pest management theory and implementation. Cabi Publishing, Wallingford

Koyama J, Kakinohana H, Miyatake T (2004) Eradication of the melon fly, Bactrocera cucurbitae, in Japan: importance of behavior, ecology, genetics, and evolution. Annu Rev Entomol 49:331-349. doi: 10.1146/annurev.ento.49.061802.123224

Kuba H, Koyama J (1985) Mating behavior of wild melon flies, Dacus cucurbitae Coquillett (Diptera: Tephritidae) in a field cage: courtship behavior. Appl Entomol Zool 20:365-372

KunYaw H, ShiCheng H, ChienChung C (2005) Effectiveness of spinosad bait in the control of Oriental fruit fly (Diptera: Tephritidae) in guava orchards. J Taiwan Agric Res 54:162-168

Landis DA, Wratten SD, Gurr GM (2000) Habitat management to conserve natural enemies of arthropod pests in agriculture. Annu Rev Entomol 45:175-201. doi:10.1146/annurev.ento.45.1.175

Le Roux K, Suzanne W (2013) Gamour: choice and setup of the pilot sites. Actes du séminaire de clôture du projet Gamour, Saint-Pierre (Reunion), pp 36-37

Lefèvre V, Capitaine M, Peigné J, Estrade JR (2014) Farmers and agronomists design new biological agricultural practices for organic cropping systems in France. Agron Sustain Dev 34(3):623-632. doi:10.1007/s13593-013-0177-2

Lienhard P, Tivet F, Chabanne A, Dequiedt S, Lelièvre M, Sayphoummie S, Leudphanane B, Chemidlin Prévost-Bouré N, Séguy L, Maron PA, Ranjard L (2013) No-till and cover crops shift soil microbial abundance and diversity in Laos tropical grasslands. Agron Sustain Dev 33(2):375-384. doi:10.1007/s13593-012-0099-4

Lindquist DA (1998) Pest management strategies: area-wide and conventional. In: Tan KH (Ed) Area-wide control of fruit flies and other insect pests. Joint proceedings of the international conference on area-wide control of insect pests, 28 May-2 June, 1998 and the Fifth International Symposium on Fruit Flies of Economic Importance, Penang, Malaysia, 1-5 June, 1998, ISBN 983-861$195-6$, pp 13-19

Liquido NJ (1991) Fruit on the ground as reservoir of resident melon fly (Diptera: Tephritidae) populations in papaya orchards. Environ Entomol 20:620-625

Liquido NJ (1993) Reduction of Oriental fruit fly (Diptera: Tephritidae) populations in papaya orchards by field sanitation. J Agric Entomol 10:163-170

Lô-Pelzer E, Bousset L, Jeuffroy MH, Salam MU, Pinochet X, Boillot M, Aubertot JN (2009) SIPPOM-WOSR: a Simulator for Integrated Pathogen POpulation Management to manage phoma stem canker on Winter OilSeed Rape. I. Description of the model. Field Crops Res 118:73-81. doi:10.1016/j.fcr.2010.04.007

Loreau M, Naeem S, Inchausti P, Bengtsson J, Grime JP, Hector A, Hooper DU (2001) Biodiversity and ecosystem functioning: current knowledge and future challenges. Science 294 (804). doi:10.1126/ science. 1064088

Maher A (1957) On the bionomics on Dacus ciliatus Loew (Diptera Trypanaeidae). Bull Entomol Soc Egypt 41:527-533

Marquier M, Clain C, Albon B, Roux E (2013) Augmentative releases of Psyttalia fletcheri (Hymenoptera: Braconidae) into cucurbit crops on Reunion Island. Actes du séminaire de clôture du projet Gamour, Saint-Pierre (Réunion), pp 148-150

Marquier M, Clain C, Roux E, Deguine JP (2014) Lâchers de Psyttalia fletcheri (Silvestri) (Braconidae: Opiinae) sur cultures de cucurbitacées à La Réunion. Cah Agric 23:188-194. doi:10.1684/ agr.2014.0704
Matanmi BA (1975) The biology of tephritid fruit flies (Diptera Tephritidae) attacking cucurbits at Ife Ife, Nigeria. Niger J Entomol 1:153-159

Mau RFL, Jang EB, Vargas RI (2007) The Hawaii fruit fly area-wide fruit fly pest management programme: influence of partnership and a good education programme. In: Vreysen MJB, Robinson AS, Hendrichs J (eds) Area-wide control of insect pests: from research to field implementation. Springer, Dordrecht, pp 671-683

McGregor AM, Vargas RI, Mau RFL (2007) An economic evaluation of the Hawaii fruit fly area-wide pest management program. USDAARS Pacific Basin Agricultural Research Center Internal Report, Hawaii, USA, $83 \mathrm{p}$

McQuate GT, Vargas RI (2007) Assessment of attractiveness of plants as roosting sites for the melon fly, Bactrocera cucurbitae, and oriental fruit fly, Bactrocera dorsalis. J Insect Sci 7:57. doi:10.1673/031. 007.5701

McQuate GT, Gretchen DJ, D. Silva C (2003) Assessment of corn pollen as a food source for two tephritid fruit fly species. Environ Entomol 32:141-150. doi:10.1603/0046-225X-32.1.141

Meerman F, Van de Veen GWJ, Van Heulen H, Breman H (1996) Integrated crop management: an approach to sustainable agricultural development. Int J Pest Manag 42:13-24. doi:10.1080/ 09670879609371963

Millenium Ecosystem Assessment (2005) Ecosystems and human wellbeing: synthesis. Island Press, Washington, DC, $137 \mathrm{p}$

Miyahara Y, Kawai A (1979) Movement of sterilized melon fly from Kume Is. to the Amani Islands. Jpn Soc Appl Entomol Zool 14: 496-497

Moonen AC, Bàrberi P (2008) Functional biodiversity: an agroecosystem approach. Agric Ecosyst Environ 127:7-21. doi:10.1016/j.agee. 2008.02.013

Moutia A (1934) Report of the Department of Agriculture: Entomological Division Mauritius, pp 25-29

Murray DAH, Miles MM, McLennan AJ, Lloyd RJ, Hopkinson JE (2005) Area-wide management of Helicoverpa spp. in an Australian mixed cropping agroecosystem, Proc. 2005 Beltwide Cotton Conf., New Orleans, National Cotton Council, Memphis, pp 1246-1251

New TR (2005) Invertebrate conservation and agricultural ecosystems. Cambridge University Press, Cambridge

Nicholls CI, Altieri MA (2004) Agroecological bases of ecological engineering for pest management, In: Gurr G, Wratten SD, Altieri MA (Eds.), Ecological engineering for pest management - advances in habitat manipulation for arthropods, CSIRO, Collingwood VIC, Australia, and CABI Publishings, Wallingford, pp 33-54

Nicholls CI, Altieri MA (2007) Agroecology: contributions towards a renewed ecological foundation for pest management. In: Kogan M, Jepson P (eds) Perspectives in ecological theory and integrated pest management. Cambridge University Press, Cambridge, pp 431-468

Nicholls CI, Altieri MA (2013) Plant biodiversity enhances bees and other insect pollinators in agroecosystems. A review. Agron Sustain Dev 33:257-274. doi:10.1007/s13593-012-0092-y

Nishida T, Bess HA (1957) Studies on the ecology and control of the melon fly Dacus (Strumeta) cucurbitae Coquillet (Diptera: Tephritidae). Hawaii Agricultural Experiment Station, University of Hawaii. Tech Bull 84:12-29

Norris RF, Kogan M (2000) Interactions between weeds, arthropods pests, and their natural enemies in managed ecosystems. Weed Sci 48:94-158. doi:10.1614/0043-1745(2000)048[0094:IBWAPA]2.0. $\mathrm{CO} ; 2$

Norris RF, Kogan M (2005) Ecology and interactions between weeds and arthropods. Annu Rev Entomol 50:479-503. doi:10.1146/annurev. ento.49.061802.123218

Norris RF, Caswell-Chen EP, Kogan M (2003) Concepts in integrated pest management. Prentice Hall, Upper Saddle River 
Orian AJE, Moutia LA (1960) Fruit flies of economic importance in Mauritius. Rev Agr Sucr Maurice 39:142-150

Papy F, Goldringer I (2011) Cultiver la biodiversité. Cour Environ l'INRA 60:55-62

Paulian R (1953) Recherche sur les insectes d'importance biologiques à Madagascar XII, les mouches des fruits. MemInst Scient Madagascar: 2-7

Pelzer E, Fortino G, Bockstaller C, Angevin F, Lamine C, Guérin D, Guichard L, Reau R, Messéan A (2012) Assessing innovative cropping systems with DEXiPM, a qualitative multi-criteria assessment tool derived from DEXi. Ecol Indic 18:171-182. doi:10.1016/ j.ecolind.2011.11.019

Pesson P (1990) Protection des cultures de la Révolution verte à nos jours: de l'empirisme à l'organisation de la lutte intégrée. In: Deux siècles de progrès pour l'agriculture et l'alimentation. Tec 1 Doc, Lavoisier, Paris

Pimentel D (2002) Encyclopedia of pest management. Marcel Dekker, New York

Pimentel D, Goodman N (1978) Ecological basis for the management of insect populations. Oikos 30:422-437

Piñero JC, Mau RFL, Vargas RI (2009a) Managing Oriental fruit fly (Diptera: Tephritidae), with spinosad-based protein bait sprays and sanitation in papaya orchards in Hawaii. J Econ Entomol 102:11231132

Piñero JC, Mau RFL, McQuate GT, Vargas RI (2009b) Novel bait stations for attract-and-kill of pestiferous fruit flies. Entomol Exp Appl 133:208-216. doi:10.1111/j.1570-7458.2009.00912.x

Popp J, Petõ K, Nagy J (2013) Pesticide productivity and food security. A review. Agron Sust Dev 33:243-255. doi:10.1007/s13593-0120105-X

Prieto-Benítez S, Méndez M (2011) Effects of land management on the abundance and richness of spiders (Araneae): a meta-analysis. Biol Conserv 144(2):683-691. doi:10.1016/j.biocon.2010.11.024

Prokopy RJ, Miller NW, Piñero JC, Oride LK, Chaney N, Revis HC, Vargas RI (2004) How effective is GF-120 fruit fly bait spray applied to border area sorghum plants for control of melon flies (Diptera: Tephritidae)? Fla Entomol 87:354-360. doi:10.1603/ 0022-0493-96.5.1485

Quilici S (1994) Programmes de recherche et d'action sur les mouches des fruits à La Réunion. Fruits 49:493-495

Quilici S, Hurtrel B, Messing RH, Montagneux B, Baret A, Gourdon F, Malvoti A, Simon A (2004) Successful acclimatization of Psyttalia fletcheri (Braconidae: Opiinae) for biological control of the melon fly, Bactrocera cucurbitae on Reunion Island: 6th International Symposium on fruit flies of economic importance (ed. by BN Barnes) Isteg Scientific Publication, Irene (RSA), Stellenbosh, South Africa, pp 457-460

Ratnadass A, Fernandes P, Avelino J, Habib R (2012) Plant species diversity for sustainable management of crop pests and diseases in agroecosystems: a review. Agron Sustain Dev 32:273-303. doi:10. 1007/s13593-011-0022-4

Ricci P, Bui S, Lamine C (2011) Repenser la protection des cultures. Innovations et transitions. Collection Sciences en partage, Éditions Quae

Risch SJ, Andow D, Altieri MA (1983) Agroecosystem diversity and pest control: data, tentative conclusions, and new research directions. Env Entomol 12:625-629

Robin MH, Colbach N, Lucas P, Montfort F, Cholez C, Debaeke P, Aubertot JN (2013) Injury Profile SIMulator, a qualitative aggregative modelling framework to predict injury profile as a function of cropping practices, and abiotic and biotic environment. II. Proof of concept: design of IPSIM-Wheat-Eyespot. PLoS ONE 8(10): e75829. doi:10.1371/journal.pone.0075829

Ros JP, Garijo C, Navarro L, Castillo E (1996) Ensayos de campo con un nuevo atrayente de hembras de la moscamediterranea de la fruta C. Capitata Wied. Bol San Veg Plagas 22:151-157
Rousse P, Ajaguin Soleyen C, Desutter V, Douraguia E, Logoras B, Moutoussamy ML, Poulbassia E, Suzanne W (2013) Gamour: technico-economic results. Actes du séminaire de clôture du projet Gamour, Saint-Pierre (Reunion), pp 52-54

Ryckewaert P, Deguine JP, Brévault T, Vayssières JF (2010) Fruit flies (Diptera: Tephritidae) on vegetable crops in Reunion Island (Indian Ocean): state of knowledge, control methods and prospects for management. Fruits 65:113-130

Ryskowski L, Jankowiak J (2002) Landscape ecology in agroecosystems management, ed. L. Ryskowski (CRC Press, Boca Raton, Florida, 2002)

Sankaram A (1999) Integrated pest management: looking back and forward. Curr Sci India 77:26-32

Sarthou JP, Badoz A, Vaissière B, Chevallier A, Rusch A (2014) Local more than landscape parameters structure natural enemy communities during their overwintering in semi-natural habitats. Agric Ecosyst Environ 194:17-28. doi:10.1016/j.agee.2014.04.018

Scherber C, Eisenhauer N, Weisser WW, Schmid B, Voigt W, Fischer M, Schulze ED, Roscher C, Weigelt A, Allan E, Bessler H, Bonkowski M, Buchmann N, Buscot F, Clement LW, Ebeling A, Engels C, Halle S, Kertscher I, Klein AM, Koller R, König S, Kowalski E, Kummer V, Kuu A, Lange M, Lauterbach D, Middelhoff C, Migunova VD, Milcu A, Müller R, Partsch S, Petermann JS, Renker C, Rottstock T, Sabais A, Scheu S, Schumacher J, Temperton VM, Tscharntke T (2010) Bottom-up effects of plant diversity on multitrophic interactions in a biodiversity experiment. Nature 468:553-556. doi:10.1038/nature09492

Scopel E, Triomphe B, Affholder F, Macena Da Silva FA, Corbeels M, Humberto Valadares XJ, Lahmar R, Recous S, Bernoux M, Blanchart E, de Carvalho Mendes I, De Tourdonnet S (2013) Conservation agriculture cropping systems in temperate and tropical conditions, performances and impacts. A review. Agron Sustain Dev 33(1):113-130. doi:10.1007/s13593-012-0106-9

Shennan C, Pisani Gareau T, Sirrine JR (2005) Agroecological approaches to pest management in the U.S. In: Pretty J (ed) The pesticide detox. Towards a more sustainable agriculture. Earthscan, London, pp 193-211

Shiga M (1989) Current programme in Japan. In: Robinson AS, Hopper $\mathrm{G}$ (eds) Vol. 3B: Fruit flies, their biology, natural enemies and control. Elsevier, Amsterdam, pp 365-374

Simon S, Rusch A, Wyss E, Sarthou JP (2014) Organic farming as an inspirational model for developing conservation biocontrol. In: Bellon S, Penvern S (eds) Organic farming, prototype for sustainable agricultures. (C) Springer Science + Business Media, Dordrecht, pp 83-105

Steiner LF, Lee RK (1955) Large area tests of male annihilation method for oriental fruit fly control. J Econ Entomol 48:311-317

Swift MJ, Izac AM, van Noordwijk M (2004) Biodiversity and ecosystem services in agricultural landscapes - are we asking the right questions? Agric Ecosyst Environ 104:113-134. doi:10.1016/j.agee. 2004.01.013

Syed RA (1969) Studies on the ecology of some important species of fruit flies and their natural enemies in West Pakistan: Pakistan Commonwealth Institute- Biological Control Station

Symondson WOC, Sunderland KD, Greenstone MH (2002) Can generalist predators be effective biocontrol agents? Annu Rev Entomol 47:561-594. doi:10.1146/annurev.ento.47.091201.145240

Thébault E, Loreau M (2005) Trophic interactions and the relationship between species : diversity and ecosystem stability. Am Nat 166(4): 95-114. doi:10.1086/444403

Thiault J, Mestres R, Larguier M (1992) L'évolution de la politique française de protection des plantes des 50 dernières années. In: Van Lenteren JC, Minks AK, de Ponti OMB (eds) Biological control and integrated crop protection: towards environmentally safer agriculture. Pudoc Scientific Publishers, Wageningen, pp 165-171 
Thompson RM, Brose U, Dunne JA, Hall RO Jr, Hladyz S, Kitching RL, Martinez ND, Rantala H, Romanuk TN, Stouffer DB, Tylianakis JM (2012) Food webs: reconciling the structure and function of biodiversity. Trends Ecol Evol 27(12):689-697. doi:10.1016/j.tree.2012. 08.005

Tixier P, Peyrard N, Aubertot JN, Gaba S, Radoszycki J, Caron-Lormier G, Vinatier F, Sabbadin R (2013) Modelling interaction networks for enhanced ecosystem services in agroecosystems. In: Woodward G, Bohan DA (eds) Ecological networks in an agricultural world. Elsevier, Amsterdam, pp 437-480

Tscharntke T, Klein AM, Kruess A, Steffan-Dewenter I, Thies C (2005) Landscape perspectives on agricultural intensification and biodiversity ecosystem service management. Ecol Lett 8(8):857-874. doi: 10.1111/j.1461-0248.2005.00782.x

Turner MG, Gardner RH, O’Neill RV (2001) Landscape ecology in theory and practice: pattern and process. Springer Science + Business Media, New York

Van den Bosch R, Aeschlimann JP (1986) L'engrenage des pesticides. Payot, Lausanne

Van Emden HF, Williams GF (1974) Insect stability and diversity in agroecosystems. Annu Rev Entomol 19:455-475. doi:10.1146/annurev. en.19.010174.002323

Van Lenteren JC, Minks AK, De Ponti OMB (1992) Biological control and integrated crop protection: towards environmentally safer agriculture. Pudoc Scientific Publishers, Wageningen

Vandermeer J (1995) The ecological basis of alternative agriculture. Ann Rev Ecol Syst 26:201-224. doi:10.1146/annurev.es.26.110195. 001221

Vargas RI, Stark JD, Kido MH, Ketter HM, Whitehand LC (2000a) Methyl eugenol and cue-lure traps for suppression of male oriental fruit flies and melon flies (Diptera: Tephritidae) in Hawaii: effects of lure mixtures and weathering. J Econ Entomol 93:81-87. doi:10. 1603/0022-0493-93.1.81

Vargas RI, Walsh WA, Kanehisa D, Stark JD, Nishida T (2000b) Comparative demography of three Hawaiian fruit flies (Diptera: Tephritidae) at alternating temperatures. Ann Entomol Soc Am 93: $75-81$

Vargas RI, Mau RFL, Jang EB, Faust RM, Wong L (2008) The Hawaii fruit fly area-wide pest management program. In: Koul O, Cuperus GW, Elliott NC (eds) Areawide IPM: theory to implementation. CAB International, Wallingford, pp 300-332

Vayssières JF (1999) Les relations plantes-insectes chez les Dacini (Diptera, Tephritidae) ravageurs des Cucurbitaceae à La Réunion. Thèse de Doctorat. Université Paris XII, Paris

Vayssières JF, Carel Y (1999) Les Dacini (Diptera: Tephritidae) inféodés aux Cucurbitaceae à La Reéunion: gamme de plantes hôtes et stades phénologiques préférentiels des fruits au moment de la piqûre pour des espèces cultivées. Ann Soc Entomol Fr 35:197-202

Veres A, Petit S, Conord C, Lavigne C (2013) Does landscape composition affect pest abundance and their control by natural enemies? A review. Agric Ecosyst Environ 166:110-117. doi:10.1016/j.agee. 2011.05.027

Vinatier F, Gosme M, Valantin-Morison M (2012a) A tool for testing integrated pest management strategies on a tritrophic system involving pollen beetle, its parasitoid and oilseed rape at the landscape scale. Landsc Ecol 27:1421-1433. doi:10.1007/s10980-0129795-3

Vinatier F, Lescourret F, Duyck PF, Tixier P (2012b) From IBM to IPM: Using individual-based models to design the spatial arrangement of traps and crops in integrated pest management strategies. Agric Ecosyst Environ 146:52-59. doi:10.1016/j.agee.2011.10.005

Weibull AC, Ostman O, Granqvist A (2003) Species richness in agroecosystems: the effect of landscape, habitat and farm management. Biodivers Conserv 12:1335-1355. doi:10.1023/ A: 1023617117780

Weiner J (2003) Ecology - the science of agriculture in the 21st century. $\mathrm{J}$ Agric Sci 141:371-377. doi:10.1017/S0021859603003605

Wezel A, Soldat V (2009) A quantitative and qualitative historical analysis of the scientific discipline agroecology. Int J Agric Sustain 7:318. doi:10.3763/ijas.2009.0400

Wezel A, Bellon S, Doré T, Vallod D, David C (2009) Agroecology as a science, movement or practice. Agron Sustain Dev 29:503-515. doi: 10.1051/agro/2009004

Wezel A, Casagrande M, Celette F, Vian JF, Ferrer A, Peigné J (2014) Agroecological practices for sustainable agriculture. A review. Agron Sustain Dev 34(1):1-20. doi:10.1007/s13593-013-0180-7

White IM, Elson-Harris MM (1992) Fruit flies of economic significance: their identification and bionomics. $\mathrm{CAB}$ International, Wallingford

Wilson EO (2002) The future of life. Knof 50-51

Woodcock B, Redhead J, Vanbergen J, Hulmes L, Hulmes S, Peyton J, Nowakowski M, Pywell RF, Heard MS (2010) Impact of habitat type and landscape structure on biomass, species richness and functional diversity of ground beetles. Agric Ecosyst Environ 139(1-2): 181-186. doi:10.1016/j.agee.2010.07.018

Wratten SD, Van Emden HF, Thomas MB (1998) Within-field and border refugia for the enhancement of natural enemies. In: Pickett $\mathrm{CH}$, Bugg RL (eds) Enhancing biological control. Habitat management to promote natural enemies of agricultural pests. Univ. California Press, USA, pp 339-374

Wratten S, Lavandero B, Scarratt S, Vattala D (2003) Conservation biological control of insect pests at the landscape scale. IOBC wprs Bull / Bull OILB srop 26:215-220

Wu J, Hobbs R (2002) Key issues and research priorities in landscape ecology: an idiosyncratic synthesis. Landsc Ecol 17:355-365. doi: 10.1023/A:1020561630963

Wyckhuys KAG, Lu Y, Morales H, Vazquez LL, Legaspi JC, Eliopoulos PA, Hernandez LM (2013) Current status and potential of conservation biological control for agriculture in the developing world. Biol Control 65:152-167. doi:10.1016/j.biocontrol.2012.11.010

Yachi S, Loreau M (1999) Biodiversity and ecosystem productivity in a fluctuating environment: the insurance hypothesis. PNAS 96:14631468

Zadoks JC (1991) A hundred and more years of plant protection in the Netherlands. Neth J Plant Pathol 97:3-24

Zadoks JC (1993) Crop protection: why and how. In: Chadwick DJ, Marsh J (eds) Crop protection and sustainable agriculture. J. Wiley \& Sons, New York, pp 48-55 